\title{
LA MIRADA ETNOGRÁFICA
}

\section{y la voz subalterna}

\author{
José Jorge de CARVALHO \\ Departamento de ANTropología, Universidad dE Brasilia \\ jorgedc@terra.com.br
}

\begin{abstract}
Resumen
[ STE ARTÍCULO PROPONE UNA EVALUACIÓN TEÓRICA Y METODOLÓGICA DE LA ANTROPOLOGÍA Y [ su lugar en el pensamiento actual de las ciencias humanas. Para ello, el autor construye la metáfora de las metamorfosis de la mirada etnográfica y detecta momentos importantes de la recepción y reproducción de ese saber generado en los países centrales en los días del colonialismo, en países periféricos. Luego de un recorrido por teóricos del pensamiento poscolonial y los estudios subalternos, como Edward Said, Gayatri Spivak y Homi Bhabha, se discuten las posibilidades de una etnografia poscolonial, centrada en la narración de voces subalternas. Finalmente, ilustra esas discusiones conceptuales con la narrativa de una mujer el estado brasileño de Maranhão y compara ese texto con la lectura que hace Heidegger de un poema de Hölderlin.

PALABRAS-CLAVE: voz subalterna, teoria postcolonial, teoría antropológica, método etnográfico.
\end{abstract}

\begin{abstract}
THE ESSAY PRESENTS A THEORETICAL AND METHODOLOGICAL ASSESSMENT OF ANTHROPOLOGY and of its place in contemporary thought in the Humanities. To do so, the author develops the metaphor of the metamorphoses of the ethnographic eye and detects some crucial moments of the reception and reproduction of this knowledge created in metropolitan centers in the days of colonialism, in periferal countries. After a review of theorists of postcolonial and subaltern studies, such as Edward Said, Gayatri Spivak and Homi Bhabha, the author discusses the possibilities of a postcolonial ethnography based on the narration of subaltern voices. Finally, he illustrates these discussions with the presentation of a narrative of a woman from the Brazilian state of Maranhão who works as a gatherer of babaçu cocoanut. He compares her text with Heidegger's reading of one of Hölderlin's poems.
\end{abstract}

KEY WORDS: subaltern voice; post-colonial theory. anthropological theory, ethnographic method.

Revista Colombiana de Antropología

Volumen 38, enero-diciembre 2002, pp. 287-328 
The story is our escort. Whitout it we are blind Does the blind man owns his escort? No, neither do we the story; rather it is the story that owns us and directs us.

(Chinua Achebe, Anthills of the Savannah)

\section{EL CAMPO TEÓRICO EN LAS CIENCIAS HUMANAS*}

A AMPLIACIÓN VERTIGINOSA DEL PANORAMA DE ESTUDIOS DE LA CULTUra en las últimas décadas ha estimulado cruces temáticos cada vez más complejos y numerosos, así como la consolidación de nuevos modos de abordar teorías y disciplinas. Los estudios culturales, por ejemplo, avanzaron en un campo fundamentalmente interdisciplinario -que abarca, inclusive, parte de lo que hasta hace unos treinta años se consideraba de interés exclusivo de los antropólogos- y, liderados por las propuestas teóricas de Stuart Hall, plantearon una nueva manera de abordar a la etnografía de las expresiones culturales contemporáneas, rehaciendo los esquemas vigentes de interpretación de materias como identidad, relaciones raciales, sexualidad, pertenencia étnica, hibridismo cultural, etcétera ${ }^{1}$.

El psicoanálisis, sobre todo en su vertiente lacaniana, expandió sus métodos de interpretación sobre las expresiones culturales, como puede apreciarse en los ensayos osados e innovadores de Slavoj Zizek -sobre todo con respecto a cine, virtualidad y cultura de masas-. Otras teorías de la imagen y del campo visual, como las de Kaja Silverman, Hal Foster, Mieke Bal y W. J. Michel han contribuido también a la renovación de las interpretaciones de la dimensión imaginativa de los símbolos culturales en la pintura, el cine, la fotografía, los pósters, etcétera. El análisis marxista de la cultura también se renovó profundamente con la obra de Fredric Jameson, en la que encontramos lecturas de textos culturales representativos,

* Traducción de Ladislao Landa Vasquez, revisada por María Teresa Salcedo, del ICANH, y Juan Andrés Valderrama.

I. Para una evaluación reciente hecha por antropólogos sobre los desafíos de los estudios culturales para la antropología, véase el libro organizado por Stephen Nugent y Chris Shore (I997). tanto de la llamada alta cultura, como de las producciones mediáticas más triviales o de puro interés comercial. La teoría del género -incluyendo la teoría feminista-desarrollada por pensadoras como Judith Butler y Gayatri Spivak subvirtió los presupuestos milenarios 


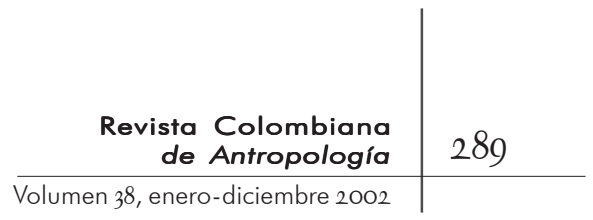

del orden cultural desde la raíz y cuestionó, mediante la formulación de una teoría densa del poder, las bases de la producción etnográfica clásica. Por último, el campo de la literatura comparada -probablemente el más vasto de todos, pues incluye, como veremos en la parte final de este ensayo, el campo de las narrativas orales tan apreciadas por los etnógrafos- permite el cruce y la ampliación de la llamada teoría crítica contemporánea con innumerables teorías del lenguaje, como las de Mijail Bajtin; del discurso, como la de Michel Foucault; de la interpretación, como las de Paul de Man; de los textos inscritos en el proyecto moderno, como las de Walter Benjamin; y de la lectura textual a contrapelo, como la actividad de deconstrucción de Jacques Derrida, que tanto ha desafiado a los cánones teóricos y disciplinares que sustentan la producción actual en las ciencias humanas.

Ante este cuadro tan vasto, abierto y fluido -apenas esbozado-de propuestas de comprensión del campo cultural, cobra una actualidad aún más radical la observación hecha por Clifford Geertz, hace dos décadas, de que el etnógrafo se mueve en un campo de géneros disciplinares difusos o imprecisos. Algunas producciones recientes en antropología visual, religión, etnopoética y etnomusicología -para mencionar sólo áreas temáticas que me son familiares- tratan de renovar sus maneras de abordar el asunto incorporando cuestiones y teorías propias de varios campos del saber mencionados antes. Sería, pues, interesante, comprender cómo se sitúa la antropología ante todas estas revisiones y combinaciones disciplinares ${ }^{2}$; considero especialmente importante indagar sobre el modo como ella ha respondido -o no-a los desafíos teórico-políticos provocados por los llamados estudios subalternos y por la teoría poscolonial, con los cuales, es de esperar, pudiésemos construir un diálogo más directo. Después de todo, este proyecto de asociar las voces de los oprimidos, de los subalternos y de los excluidos fue, justamente, la promesa hecha por una generación anterior de antropólogos, de una práctica etnográfica crítica de las condiciones coloniales en que se plasmó la disciplina. A continuación intentaré discutir el marco conceptual de la mirada etnográfica, contrastando sus metamorfosis con la teoría poscolonial reciente.

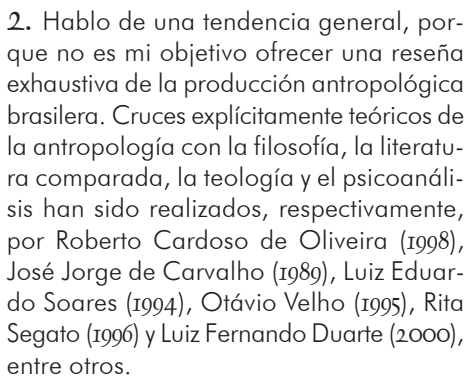

2. Hablo de una tendencia general, porque no es mi objetivo ofrecer una reseña exhaustiva de la producción antropológica brasilera. Cruces explícitamente teóricos de la antropología con la filosofía, la literatura comparada, la teología y el psicoanálisis han sido realizados, respectivamente, por Roberto Cardoso de Oliveira (I998), José Jorge de Carvalho (I989), Luiz Eduardo Soares (I994), Otávio Velho (I995), Rita Segato (I996) y Luiz Fernando Duarte (2000), entre otros. 


\section{Metamorfosis DE LA Mirada ETNOGRÁficA}

$$
\text { C }
$$

OMO BIEN DIJO JACQUES DERRIDA, LA MIRADA ETNOGRÁFICA FUE REsultado de un descentramiento en la visión occidental del mundo después de la era clásica, "en el momento en que la cultura europea fue desplazada, expulsada de su lugar, dejando entonces de ser considerada como la cultura de referencia” (I97I: 234). Tal como leo ese esquema -utilizándolo para construir mi propio argumento-, uno de los efectos epistemológicos de consecuencias políticas más profundas de este descentramiento fue la separación de las miradas de los dos sujetos construidos por la disciplina: la del etnógrafo -el civilizado- y la del nativo mirado por él -el primitivo-, cuyas naturalezas parecían, en la perspectiva de quien miraba, intercambiables analíticamente y, al mismo tiempo, inconmensurables existencialmente.

La cuestión de cómo mira el primitivo no se puso en discusión en aquel momento fundacional, habiendo quedado implícito, en la teoría, que la mirada del primitivo sobre sí mismo y su entorno era una mirada natural: inmediata, directa, irreflexiva. Se partía del presupuesto de que la hermenéutica primitiva poseía límites muy bien definidos, mientras que el teórico presentaba su horizonte interpretativo como un movimiento racional de expansión infinita. Derrida pudo afirmar entonces que la etnología es etnocéntrica, a pesar de combatir el etnocentrismo, porque el occidente, al mismo tiempo que practicó ese descentramiento, construyó su imagen frente al resto del mundo como la única cultura capaz de realizar tal movimiento de apertura y autodesdoblamiento.

La antropología que se estableció como disciplina académica en los países centrales a inicios de siglo surgió de ese doble movimiento. Mucho más tarde, con su politización creciente a partir de las luchas antiimperialistas y poscoloniales, pudo sustentarse el argumento de que el nativo construye su alteridad respondiendo críticamente, desde un lugar subalterno, a la mirada del colonizador. Además, el proyecto de universalización de la disciplina, a partir de su descentramiento original, comenzó a ser cuestionado al consolidarse las tradiciones nacionales de la antropología en los países periféricos: en esos dominios no occidentales $-\mathrm{O}$ a veces no enteramente- los antropólogos se encontraron con la tarea de tener que inscribirse a sí mismos, y 


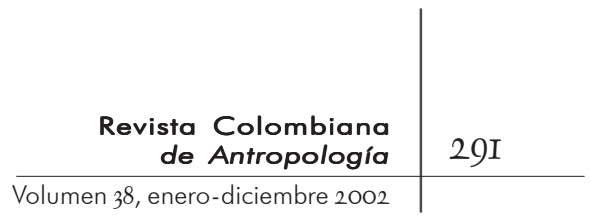

a sus nativos objeto de estudio, en un espacio existencial que había sido asumido, por lo menos idealmente, como común a ambos: la nueva nación que debía ser consolidada.

Eso provocó un segundo descentramiento dentro de la estructura originalmente descentrada de la disciplina: los etnógrafos de los países periféricos habían aprendido con sus maestros de los países centrales la teoría de la mirada descentrada, que presuponía fijar el punto de fuga de esa perspectiva universalista en la cultura occidental europea. Así, el proyecto de universalizar la disciplina pasó a sumarse-muchas veces en discordia con las intenciones de los maestros- a un proyecto neocolonial más general de occidentalización del mundo ${ }^{3}$. ¿En qué medida esas naciones periféricas son o no, hoy en día, una continuación de occidente y cuál es el significado de ser o no una continuación del mundo occidental para la conformación de un saber de pretensiones universales surgido en Europa? A partir de estas cuestiones se constituye contemporáneamente un gran campo de disputa teórica e ideológica que atraviesa prácticamente todo el saber académico, incluyendo la historia, la geografía, la literatura, la filosofía, las artes y, por qué no, la antropología. Todas esas disciplinas, tanto en los países centrales como en los periféricos, están involucradas ahora en la tarea de descolonización de los paisajes mentales, lo que implica la revisión radical de sus cánones teóricos y temáticos ${ }^{4}$. Lo que importa subrayar aquí, para dar continuidad a la discusión central, es, apenas, que esos dos nativos -el sujeto y su objeto de estudio etnográfico- negociaron su encuentro existencial en esa encrucijada de ultramar, en la que se influenciaron mutuamente, de un modo siempre tenso, una historia -colonial y poscolonial- y un espacio nacional específicos. Resalto el carácter específico de ese encuentro para enfatizar sobre los dos polos de ese segundo descentramiento: por un lado, el vínculo con el descentramiento original, que permitió la recreación -crítica o

3. Para dos críticas actuales al proyecto de occidentalización del mundo, véanse Serge Latouche (I996) y el ensayo aún más radical de Ziauddin Sardar (I998).

4. Gayatri Spivak señaló con precisión la aporía sobre la cual reside la construcción de ese lugar de verdad por parte de la antropología: "Si nos relacionamos con algo como conocedores, como gente estudiada-le sujet supposé savoir, el sujeto de la producción de conocimiento- es imposible tener una relación distinta con el aprender. En la historia de la antropología, ningún antropólogo ha sido capaz de sugerir que existe una cognición en la cultura estudiada, equivalente a la razón europea. Ellos han criticado la razón europea, pero nadie ha sido capaz de sustituirla. Por otra parte, no es verdad que no haya conocimiento en otras partes. No es posible descubrirlo mientras uno continúa siendo le sujet supposé savoir. La razón no fructifica" (Danius y Jonsson, 1993: 44). 


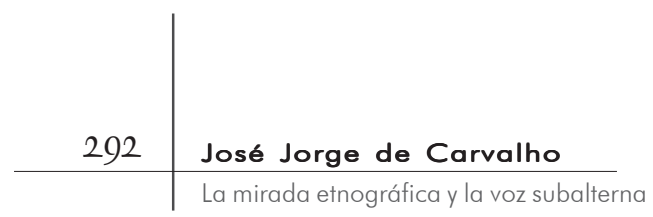

acrítica- de la antropología fuera de las metrópolis occidentales; y por otro, una enorme variedad de modos de ser etnógrafo nativo, lo que condujo a tradiciones antropológicas muy diversas, tales como la india, la australiana, la canadiense, la mexicana, la brasilera, etcétera ${ }^{5}$.

Este aspecto despeja un panorama teórico de metáforas visuales de gran complejidad, si intentáramos realizar una descomposición milimétrica de todas las posibilidades de esas miradas: frontales, contiguas, unidas, cruzadas, verticales, desde abajo hacia arriba, paralelas, invertidas, oblicuas, difusas, sesgadas. Diré sólo que es posible hacer corresponder cada una de ellas a una crisis específica de la autoridad etnográfica. No cabe aquí hacer un recuento histórico exhaustivo de esa secuencia de miradas, y por eso pasaré rápidamente, de forma sintética, cuando no elemental, por algunos de los momentos determinantes -incluyendo una de sus versiones actuales- de esa visión humanista intensa que es la perspectiva antropológica. Adapto aquí la clásica distinción de Lacan (I998) entre tiempo lógico y tiempo cronológico; de hecho, convivimos hoy en día con todos los tiempos teóricos, los que intentaré identificar históricamente.

Un momento de la teoría antropológica que ha sido emblemático de su práctica como disciplina puede ser ilustrado por la obra de Franz Boas, o aún mejor, está encarnado, para nosotros, en su discípulo Melville Herskovits, quien hizo investigación de campo en Brasil. Ambos, etnógrafos incansables y difusores de métodos y técnicas de investigación de campo muy rigurosas, ejercieron

5. Resalto las consideraciones metadisciplinares, partiendo de presupuestos teóricos distintos de los que planteo, de Roberto Cardoso de Oliveira. Sobre la construcción de las antropologías periféricas, véanse Oliveira (I998); y Oliveira y Ruben (I995); sobre la antropología en India, véase Peirano (I995); y en Australia y Canadá, Baines (1995 y 1996).

6. Paul Rabinow (1983) llegó a sostener que la posición política de Boas fue más progresista aún que la de Clifford Geertz, discutida más adelante. un papel importante como mediadores de sus respectivos nativos y expresaron una enorme simpatía por la condición de los indios de Canadá y Estados Unidos, así como de los negros del nuevo mundo ${ }^{6}$. Con todo, en ese primer estilo de mirada el etnógrafo indaga por la alteridad sin registrar ninguna falta esencial de su ser -en el sentido lacaniano de falta- en relación con la cultura y la sociedad del nativo mirado por él; la cultura ajena, aunque respetada, es, básicamente, objetivada: la mirada no presupone que el nativo esté implicado en la reproducción del horizonte de vida del propio etnógrafo. 


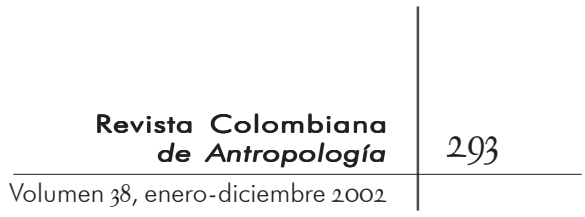

Un segundo modo de mirar, que estimuló una generación entera de etnógrafos y teóricos, fue marcado por la obra de Claude Lévi-Strauss, quien encarna la mirada científica de las instituciones culturales en su estado casi puro: el famoso kantianismo sin sujeto trascendental, tal como denominó Paul Ricoeur esta manera de abordar. Con todo, en ciertos pasajes de Tristes trópicos texto que inscribió nuestro país en el llamado orden etnográfico universal- él incorporó también momentos de nostalgia y subjetividad. "Nuestros indios están desapareciendo", dicho por LéviStrauss, pasa a ser una disglosia, en el sentido bajtiniano, cuando leemos: somos nosotros, como brasileros quienes hablamos junto con él; o de cierto modo es él, en su mítica lucidez de autor, quien resuelve hablar por nosotros, neófitos en el juego antropológico surgido en occidente.

Por otro lado, en los últimos años Lévi-Strauss decidió retirarse, aunque intermitentemente, de ese lugar seguro de maestro de mirada distante que encarnó por casi medio siglo. A contrapelo del emblemático relativismo cultural se ha declarado preocupado con la "invasión de valores ajenos a la cultura francesa” provocada por la presencia de árabes y africanos de religión musulmana en Francia. Al situarse como ciudadano sobre un asunto de convivencia y no de estructura, se deja involucrar no sólo como sujeto, sino también como objeto en las polémicas francesas sobre identidad nacional, encuentros culturales, choque de civilizaciones, alteridades, etcétera. Más que juzgar el contenido de sus declaraciones lo que importa aquí es constatar el abandono -que ya había ocurrido en los países periféricos-, en un país central, de la hipotética inconmensurabilidad existencial entre etnógrafo y nativo, fundamental para legitimar la autoridad de esa construcción histórica de una etnología como ciencia. Al situarse en una polémica eminentemente política, Lévi-Strauss abre el espacio para que aquellos que antes eran los primitivos o nativos -el árabe, el africanopuedan ahora devolver la mirada que por tanto tiempo los construyó unilateralmente. Esa crisis de autoridad nos conduce a examinar otra metamórfosis de la mirada etnográfica.

Un tercer momento de cambio de la mirada, también muy estudiado en Brasil, se consolidó en la década de I980. Es el momento de la crítica a la construcción de la autoridad etnográfica realizada por la antropología estadounidense, que fue capaz de devolver inclusive, y de cierto modo, una crisis gestada 


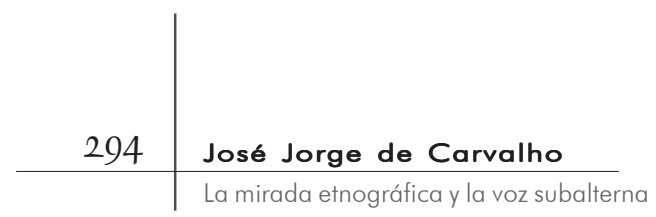

en la antropología europea -sobre todo británica-, que hasta hoy encuentra cierta dificultad en asimilar los desafíos provocados por los llamados posmodernos en relación con la posición privilegiada del autor, que implica una posición privilegiada del sujeto moderno, capaz de mirar el mundo todo, desde el punto de vista de ese lugar, pretendidamente seguro, de verdad (véanse Clifford y Marcus, 1986; y Marcus y Fischer, 1986). Me parece que ese momento, aunque muy estudiado entre nosotros, ha sido puesto en práctica pocas veces. A pesar de que la crisis del lugar seguro del autor ha sido una de las principales razones para el planteamiento de esa nueva modalidad de mirada etnográfica, su asimilación en Brasil se dio más en el ejercicio de la introducción de la subjetividad que en la discusión epistemológica sobre la reflexividad. O sea, aquello que fue, básicamente, un cuestionamiento radical de la autoridad -vista como indiscutible- del etnógrafo se redujo a una discusión sobre cómo incorporar la saga biográfica del autor en el texto etnográfico y en su interpretación. Las discusiones se desplazaron en parte desde los criterios empíricos de verdad los que incidirían directamente en la evaluación del rendimiento alcanzado por los modelos interpretativos propuestos- hacia los criterios éticos de compromiso personal, simpatía, empatía, etcétera, aspectos enfocados en general con mucho entusiasmo y creatividad.

No puedo entrar en los detalles de por qué la cuestión de la autoridad del antropólogo no se ha planteado todavía en Brasil. Otávio Velho se refirió a una especie de homogeneización de nuestra comunidad, y ese hecho, justamente, no permitiría esa crítica, porque ella llevaría a la formación de grupos de interés y a una definición más clara de posiciones teóricas -que son siempre políticas- y a polémicas mucho más explícitas, lo que, por una estrategia del grupo de antropólogos brasileros, no se desea que acontezca (véase Vagner Gonçalves da Silva y Letícia Vidor Reis, I996). Lo que se incorporó, entonces, fue una especie de empatía con el nativo: los etnógrafos colocándose subjetivamente en su investigación de campo, pero siempre aspirando a preservar para sí el lugar de autor seguro e irrefutable.

Una de las pocas excepciones -sintomáticamente bastante inspiradora- que conozco es el volumen Antropologia e seus Espelhos, de 1996, no muy divulgado aún. Este texto es el resultado de un debate que hubo en la USP en 1994, en el cual tuve el placer de participar (véase Vagner Gonçalves da Silva y Letícia 


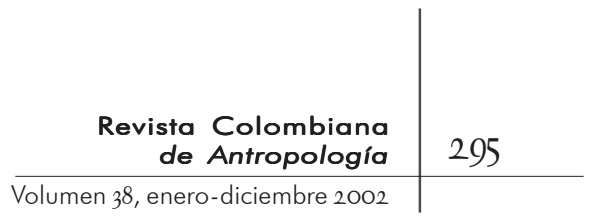

Vidor Reis, 1996). En él hablaron alumnos del posgrado en antropología de la USP, tradicionalmente tomados como nativos por los antropólogos: país-de-santos, indios, capoeiristas, líderes sindicales y feministas, interesados todos, justamente, en devolver esa mirada de autoridad del saber moderno y dislocado, de Europa y de Estados Unidos, a Brasil. Esa devolución de la mirada produjo un texto rico, lleno de interés y todavía bastante original en nuestro medio ${ }^{7}$. Entre otras cosas, nos invita a meditar sobre la bajísima presencia de negros, indios o de sus descendientes directos y, en general, de estudiantes oriundos de las clases menos favorecidas de nuestra población en nuestros cursos de posgrado. En verdad, en comparación con la politización provocada por la acción afirmativa y sus múltiples derivaciones de críticas calcadas de la construcción de identidades -raciales, étnicas, de género, sexuales, etcétera, que forman parte en este momento de toda la antropología del primer mundo-, nuestra comunidad antropológica es aún muy refractaria a cualquier cuestionamiento sobre su lugar clásico, similar al descrito, de autoridad indiscutible y de pertenencia acrítica a la elite social del país ${ }^{8}$.

Llama la atención, inclusive, el hecho de que el texto de Derrida antes citado -un ensayo seminal en las ciencias humanas en la presente generación, a pesar de que se publicó en Brasil hace casi treinta años- no haya recibido aún reacción alguna -que conozca-, por parte de nuestros teóricos de la antropología. Una excelente exégesis de su aplicación para una crítica de la etnografía, como acto de traducción cultural, fue realizada más recientemente por Tejaswini Niranjana en su libro Siting Translation (I995). Este texto está ausente también -de un modo para mi más sorprendente, dada la pretensión de exégesis y crítica de los autoresde los dos principales manuales de teoría crítica de la antropología estadounidense de los años I980 (véanse Marcus y Fischer, I986, y Clifford y Marcus, I986), que tanta influencia tuvieron en la antropología brasilera. Por tanto, me interesa, en primer lugar, registrar su ausencia entre nuestros textos teóricos.

7. Otro rico ejemplo de ese espejo de la antropología es el documento Rouch in Reverse, del cineasta maliense Manthia Diwara (I995), en que ejercita lo que denomina una antropología a la inversa, en la cual lo que antes era el objeto de investigación -en este caso el africanoestudia a su investigador -en este caso Jean Rouch-.

8. Obviamente, muchos antropólogos brasileros construyen un espacio paralelo de activismo junto a las comunidades que estudian. Lo que discuto aquí es la resistencia a incorporar explícitamente la crisis de los autores y de las formulaciones teóricas y etnográficas ejercitadas. 


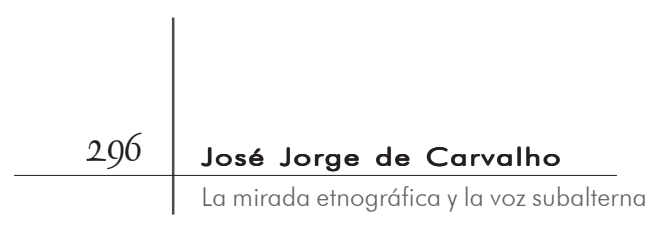

Si definimos a partir de ahí la disciplina antropológica como un lugar donde se confrontan valores -y no más como la diseminación o adaptación de un valor construido en un determinado momento de la historia del occidente europeo- estamos obligados a recurrir a una gramática alternativa para definir principios como solidaridad, fraternidad, derechos individuales y colectivos, discriminación, etcétera ${ }^{9}$. Nos vemos implicados todos en esa discusión sobre los valores; el lugar descentrado ya no lo ocupa nadie y el desafío ahora es cómo relegitimar el saber académico a partir de esa base conmutativa de miradas. Es lo que mencionamos antes sobre las afirmaciones de Lévi-Strauss acerca de los árabes y africanos en Francia. El saber filosófico contemporáneo atraviesa una crisis

9. Otávio Velho (rg95) ha sugerido la impor- análoga cuando se lee en el nuevo tancia que tiene para la antropología la dis- libro de Jacques Derrida, El monocusión sobre los valores. lingüismo del Otro (1997), cómo dejó de ser la mirada reveladora de un filósofo del primer mundo, y pasó a ser la mirada marginal de un judío francés argelino que relata las amarguras que sufrió en la infancia, al someterse a un proceso de educación monolítica y monológica en francés, a costa de reprimir el uso letrado de su lengua materna. Toda esa cuestión de entregarse a una verdadera fuga del lugar centrado, hegemónico -caricaturizado en la mirada masculina, blanca, europea, construida en las colonias como la mirada universal-, suele ser más complicada en la periferia que en la metrópoli, porque se construyó con más energía esa ilusión de un lugar puramente académico. ¿Quién estudia qué, sobre quién?; ¿y quién sabe cuáles aspectos de su realidad -cultural, social, política, ambiental, económica- están siendo estudiados por quién? El ejercicio etnográfico puede reconstruirse y evaluarse ahora entre esos qué y quiénes, que implican posicionalidad -para utilizar un término de Stuart Hall (I996)- y definición explícita de la situación del autor en el juego geopolítico -para usar una expresión central en el argumento de Walter Mignolo (I994 y 1998) y de otros autores poscoloniales-.

Muchos lectores se preguntarán por qué no privilegié el lugar teórico de Clifford Geertz, tal vez el mayor ícono del saber antropológico entre nosotros. Geertz introduce, de hecho, una crítica al positivismo inscrito en el primer modelo de mirada -y aún en el segundo-, pero su práctica de reflexión es compatible con lo que describí hasta ahora. George Marcus repitió recientemente 


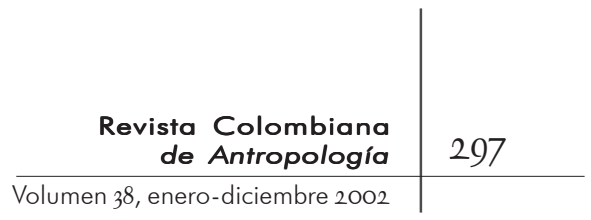

su evaluación anterior de la contribución original de Geertz a la práctica etnográfica, refiriéndose a la introducción de su célebre texto sobre la pelea de gallos en Bali (véase Geertz, 1995). Sin duda alguna muy eficaz, aquel artificio de complicidad fue mucho más una innovación en las estrategias retóricas de legitimación del lugar privilegiado del autor que una propuesta de insurrección contra la estructura fundacional de la disciplina, tal como fue formulada por Derrida en el pasaje citado. En Geertz no hay ningún cambio en la geopolítica de la disciplina antropológica como un saber formulado en el primer mundo que se expandió dentro de una estructura de poder, cuyos moldes trato de delinear mediante la metáfora de las miradas. En el texto sobre la pelea de gallos él se dejó implicar existencialmente en el nivel de la aldea; delimitó para sí una frontera muy conveniente del contexto en el que ejerció su hermenéutica, cuando sabemos muy bien, por Hans George Gadamer, Jonathan Culler, Gerald Bruns, Rodolphe Gasché y tantos otros, que el contexto jamás tiene límites y es justamente en la construcción de sus fronteras que podemos captar las negativas del sujeto a implicarse en la realidad que interpreta.

Geertz fue protegido, supuestamente, por los nativos de las masacres ocurridas en los tiempos del golpe en Indonesia; pero quedó fuera la intervención directa de Estados Unidos en la construcción y manutención del régimen de terror bajo el cual vivían, durante su trabajo de campo, sus queridos aldeanos -con todas las mediaciones jerarquizantes, las complicidades y las capilaridades que caracterizan esos regímenes dictatoriales, tan conocidos por nosotros-. Lo que él hace en su último ensayo, After The Fact, es construir un esquema sofisticado de detour para reproducir, con un nuevo lenguaje, la condición de etnógrafo del centro del mundo heredada de sus maestros (véase Geertz, I995). George Marcus, al mostrar las limitaciones críticas de la brillante propuesta ensayística de Geertz, no le reprocha tampoco la despolitización del contexto que presentó como marco de su etnografía ${ }^{10}$. Dicho de otro modo, Marcus, en cuanto exégeta de la teoría antropológica, no somete a Geertz a una crítica poscolonial. Más aún, es claro que él no retira a Geertz de su lugar de "sujeto de la producción de conocimiento"-le sujet supposé savoir de Lacan, citado

IO. Esta censura es explícita, por ejemplo, en la reseña de Local Knowledge, hecha por el keniano Ngugi Wa Thiong'o, uno de los escritores más importantes del África contemporánea y militante radical de la tarea de descolonización del horizonte de valores de la elite intelectual africana (véase Ngugi, I98I). 


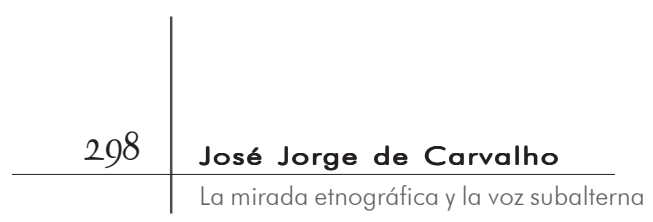

por Spivak-, porque al hacerlo tendría que retirarse él también de ese lugar ${ }^{11}$. El ejercicio de intentar rehacer las condiciones de producción del sujeto, supuesto saber del antropólogo, inaugura un nuevo momento de esa metamorfosis de miradas. Intentaré definirla como la perspectiva etnográfica poscolonial.

\section{LA MIRADA POSCOLONIAL}

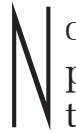

O TENGO ESPACIO PARA ENTRAR EN LA DISCUSIÓN DE LA PERSPECTIVA poscolonial. El teórico argentino Walter Mignolo (I996) sostiene que tuvimos nuestros teóricos poscoloniales mucho antes de que surgieran esos famosos académicos de lengua inglesa de hoy. Él habla de una generación anterior que incluye a intelectuales como José Carlos Mariátegui, Rodolfo Kusch, Paulo Freire y a otros vivos aún como Leopoldo Zea y Enrique Dussel, que pueden entenderse según los mismos criterios con los que comprendemos a pensadores como Gayatri Spivak, Homi Bhabha, Edward Said, Aijaz Ahmad, Ngugi Wa Thiong'o, es decir, como pensadores poscoloniales. El problema es que ellos se construyeron como teóricos antes de la inscripción de la etnografía como práctica sistemática en la academia latinoamericana. Lo que debemos hacer ahora es proponer una nueva agenda etnográfica que recupere explícitamente su crítica a nuestra posición de periferia de occidente. Eso nos permitiría un intercambio intelectual más directo con los teóricos poscoloniales del primer mundo, pues ellos ya incorporan como

II. De todas maneras, en un ensayo más reciente, Marcus admite que la crisis de representación en la antropología debe incorporar la discusión de la condición subalterna y proponer rehacer el proyecto etnográfico a partir de algo parecido a lo que llamé una base conmutativa de miradas: "La auto percepción de las prácticas de la etnografía como un poder/saber, entre y con clases específicas de conexiones con los otros, basada en ciertos compromisos e identificaciones éticos, forza la refiguración del terreno de investigación -desajusta posiciones normativas, en las que el concepto de las elites, del antropólogo y de los subalternos se reacomoda" (Marcus, 1997: 424). uno de sus puntos de crítica los textos etnográficos de sus regiones de origen subcontinente indio, África, mundo árabe, etcétera-. Por esa razón, pienso que esos autores nos proponen el gran desafío de revisar nuestra situación geopolítica dentro del campo de fuerzas de la producción intelectual contemporánea.

Aún más, según Mignolo, el proyecto fundamental de los teóricos poscoloniales latinoamericanos de antes era la tarea de la descolonización, tarea que se dejó de lado por un buen tiempo, con el incremento de nuestra permeabilidad a 


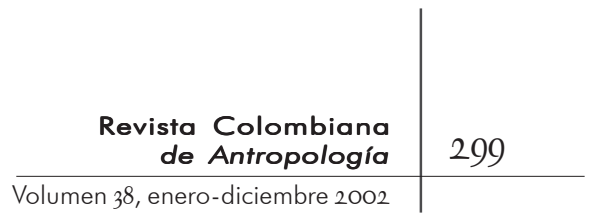

la mirada envolvente de la antropología europea y, más recientemente, estadounidense. Me gustaría reintroducir ese desafío porque pienso que podría ayudar a ampliar nuestro campo actual de reflexión. El objetivo principal de la mirada poscolonial es luchar, como dice Mignolo, por un desplazamiento del locus de enunciación desde el primer al tercer mundo. El interés está en la relocalización; no se trata apenas de devolver la mirada lo que es, hasta cierto punto, la alternativa propuesta por la crítica de la reflexividad en las etnografías- sino de intentar cambiar el origen de la mirada, ejercitando así lo que él llama hermenéutica pluritópica ${ }^{12}$.

A continuación me referiré, brevemente, a una autora y dos autores de la nueva teoría poscolonial, que nos ayudan a recuperar discusiones que ya tuvimos en Brasil y que han sido un tanto silenciadas en las últimas dos décadas. La primera es Gayatri Spivak, cuya trayectoria teórica más importante pasa también por el propio hibridismo identitario que ella misma explicita. Su proyecto teórico-político se relaciona con su necesidad biográfica de deshacer el doble

I2. Para la conceptualización de la hermenéutica pluritópica, véase Mignolo (I994). lugar de habla subalterna que le ha sido impuesto desde la infancia, como mujer en una nación colonizada. La arena discursiva y el campo en el cual se conducía todo el debate sobre la subjetividad contemporánea, tanto por el colonizador como por el colonizado, estaba centrada en occidente. El interés de Spivak es rehacer esas coordenadas y llevar el debate a otro lugar, con lo que toca una cuestión central que debemos retomar: discutir la capacidad que tiene el subalterno de representarse. Dicho de otra forma, teorizar cuáles son sus posibilidades de subjetivarse autónomamente. Su texto clásico "Can the subaltern speak?" (I993a) es una tentativa de rehacer un debate de extrema complejidad mediante la articulación de la teoría marxista con el psicoanálisis y la deconstrucción derrideana. Eso implica, una vez más, conquistar un espacio de enunciación, asegurar un lugar para el discurso, entendido como un lugar privilegiado en esa batalla por una subjetivación ecuánime. Este proyecto de Spivak ha sido criticado muchas veces como mero ejercicio académico fascinante disfrazado de batalla política. En mi lectura, con todo, en él se funden -ineludiblemente- teoría brillante y activismo junto a los sectores subalternos. 
La condición subalterna es la condición del silencio, de ahí la discusión de la autora sobre los dos términos utilizados por Karl Marx en el Dieciocho Brumario de Luis Bonaparte para definir el sentido de representar: la Vertretung, que es la representación en cuanto un poder pasado a terceros, típica de la representación política de las minorías frente al estado; y la Darstellung, que es la representación como el modo en que el portavoz retrata a los sujetos representados por él, quien inevitablemente debe autorepresentarse también como sujeto histórico en ese proceso, en la medida en que deberá identificarse como miembro de la categoría genérica de sus representados (para el esclarecimiento de estos términos, véase Spivak, I990: I08-109).

En el caso de la Vertretung asistimos al dilema constante en el que están las clases oprimidas, de necesitar mediadores para ser consideradas actores legítimos de reivindicación. Por su propia condición de silenciado, el subalterno carece, necesariamente, de un representante. En el momento en que se entrega sólo a las mediaciones de representación de su condición, se torna en un objeto en las manos de su apoderado en el circuito económico y de poder, y con eso no se subjetiva plenamente. En el capitalismo, el individuo que no controla los medios de producción se hace representar, no en tanto sujeto, sino en tanto valor de cambio. Paradójicamente, su legitimidad pasa a ser dada por otra persona, que toma su lugar en el espacio público, esencializándolo como el lugar genérico del otro del poder. De ahí la búsqueda constante por aprehender el momento en que la re-presentación se funde con la presentación, pues es especialmente propicio para el surgimiento de procesos de insurrección y de movimientos sociales no asimilados y revolucionarios, en la medida en que las clases subalternas intentarán controlar el modo en que serán representadas. Formular una teoría del sujeto de la conciencia deliberativa soberana y teñirlo de la condición específica de coparticipación de la teórica feminista con los subalternos e insurgentes -en este caso, las mujeres-, he aquí una síntesis de la agenda radical de Spivak, que tiene resonancias de nuestras discusiones, un tanto olvidadas últimamente, sobre el etnógrafo comprometido, militante, aunque crítico de las agendas anteriores de la antropología aplicada.

Lo que más me motiva a recuperar de los textos de Spivak -y, en general, de los autores de los grupos de estudios subalternos 


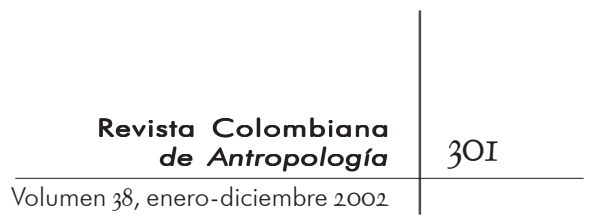

indios que intentan rehacer el lugar de su relación con el mundo británico- no es tanto su discusión sobre India ${ }^{13}$. Además de esta agenda tan fértil, me parece contundente su discusión sobre la quema de las viudas -el famoso ritual del sati-, tanto con los indios tradicionalistas como con los colonialistas ingleses. Al responderles, ella invoca un horizonte de significantes que la distingue por completo de cualquiera que se dispusiese a realizar esa tarea utilizando sólo los recursos intelectuales generados en la llamada civilización occidental. Ella sostiene que el significante sati viene de los Vedas y del Dharmasastra, textos sagrados de más de tres mil años de antigüedad. Al reinterpretar un significante de tan larga duración, construye un soporte hermenéutico que desafía la pretensión de la modernidad europea de resolver teóricamente las cuestiones planteadas por los pensadores de hoy, independiente de dónde se sitúan. Esa profundidad temporal repone centrípetamente el carácter periférico de su condición de india. Considero que este es uno de los argumentos más poderosos que ella nos presenta desde el punto de vista de la contrahegemonía teórica. Se sitúa en un lugar de privilegio, porque puede hablar como heredera de una civilización más antigua que la de los países europeos y del nuevo mundo. Al hacerlo, descompone y deconstruye una serie de mitos sobre quién habla en primer lugar, en el lugar privilegiado. Además, cuando introduce el libro de la escritora india Mahasweta Devi, Imaginary Maps, traducido por ella, muestra que los escritores indios representan mejor que cualquier escritor occidental los ideales de las narrativas posmodernas. En fin, colocándose en el centro y distanciándose de él, en cuanto sujeto de habla, mina la autoridad del centro-qua-occidente.

Otro teórico que ha sometido la tradición etnográfica a una crítica poscolonial es Edward Said ${ }^{14}$, quien propone -y lleva a cabo- un cambio radical de identificación de la mirada. Más que eso, consigue situarse en la teoría a partir de una

I3. El Grupo de estudios subalternos de India fue organizado en torno de la figura del historiador Ranajit Guha. Para una comprensión de su agenda véase Guha (I997). Su proyecto inspiró el surgimiento de grupos similares en otras partes del mundo, inclusive el Grupo de estudios subalternos de América latina, cuyo manifiesto de fundación fue publicado en Boundary 2 , en un volumen dedicado al debate sobre el posmodernismo en América latina (véase Latin American Subaltern Studies Group, I993).

I4. Mignolo, Spivak, Said y Bhabha son teóricos poscoloniales que residen y son profesores en Estados Unidos. Todos cuestionan el modo como el pensamiento europeo subjetivó, también en una relación de subalternas, las demás regiones del mundo, inclusive la nuestra. Con todo, la mayor atención ha sido prestada, hasta ahora, al subcontinente indio, a Africa, Oceanía Oriente Medio y al mundo musulmán, quedando América latina aún poco representada en esa nueva red de teorización sobre la fase actual de la descolonización del mundo. 


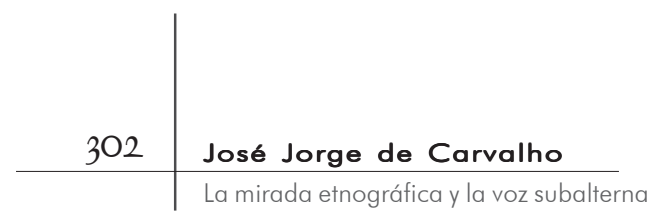

mirada que no es la que se centra en la modernidad europea. De su obra multifacética destaco su análisis, muy agudo y original, del clásico Mansfield Park, de Jane Austen. Al contrario de la lectura más convencional de esa novela -la descripción de las costumbres inglesas del siglo diecinueve- Said procura demostrar que en ella hay un signo horroroso, siniestro, aunque muy discreto: mientras se discute cómo transformar aquella mansión de provincia en un lugar idílico, casi edénico, el señor de la casa debe desplazarse de prisa al Caribe, para sofocar una rebelión de esclavos en una de sus plantaciones. Así, la propuesta de vida perfectamente civilizada que es Mansfield Park se basa en la más horrible de las prácticas humanas e imperiales, la esclavitud. Es un Edén que siempre carga un infierno dentro de sí.

Como retomaré en la parte final de este artículo, el texto cultural que se pretende mostrar como modelo universal trae incrustada dentro de sí, bajo un signo de horror, la presencia de los oprimidos y silenciados por los sujetos mismos que celebra. Said sostiene que ese potencial de extrema negatividad es una constante en las grandes obras literarias y artísticas de los países imperiales, y define su método de análisis de esas obras canónicas como una lectura contrapuntística: el texto metropolitano sólo puede comprenderse en toda su complejidad simbólica e ideológica cuando se ve a la luz de su negativo - o, mejor, de su contrapunto, para proseguir con su metáfora musical, es decir, la reacción musical a la textualidad metropolitana-. Su punto de partida en ese ejercicio de crítica poscolonial es el texto del colonizador. Según lo que trataré de desarrollar más adelante, un proyecto etnográfico sensible a la condición colonial invertiría esa pieza analítica-musical y colocaría, como aspecto inicial, precisamente en contrapunto, el texto periférico.

La posición de Said es muy conocida en Brasil, y en nues-

I5. Véase mi ensayo sobre el imperialismo cultural estadounidense, en el que esbozo un análisis de las condiciones de reproducción actual de nuestra academia, dentro de la geopolíitica de las relaciones de Brasi con Estados Unidos (Carvalho, 1997). Otro texto que merece mayor atención es el ensayo de Roberto Kant de Lima sobre su experiencia como alumno de doctorado en antropología en Estados Unidos, en el que trata el esquema de la reproducción en el primer mundo de los antropólogos residentes en las naciones periféricas. tros cursos de posgrado se leen sus libros más importantes de crítica a la hegemonía occidental, como Orientalismo e Imperialismo y cultura. Con todo, son pocos los académicos brasileros que utilizan la categoría imperialismo para analizar nuestra relación con el primer mundo y, más particularmente, con Estados Unidos ${ }^{15}$. En la actualidad, ese imperialismo está menos 


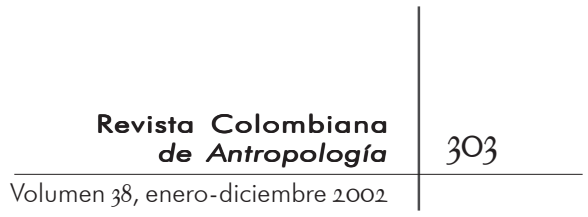

disfrazado que nunca y llega, prácticamente, a todas las aéreas de la vida pública del ciudadano brasilero y de sus relaciones con el estado. El contenido de los medios de comunicación, las leyes de patentes, la internacionalización de la amazonia, el control del modelo económico nacional, la privatización de la educación superior y el desmonte de las instituciones de investigación, el modelo de relación entre el ciudadano y el estado, la manera en que la sociedad debe organizarse democráticamente, los movimientos negros, feministas, indígenas y ecologistas, todos ellos, sufren de alguna manera una enorme presión, cuando no coerción directa, para que se adecuen a los patrones de valores propuestos por Estados Unidos. Nosotros, como buenos académicos contemporáneos, leemos una obra como Imperialismo y cultura, entendemos perfectamente la importancia del asunto allí tratado y callamos frente al imperialismo al que estamos sometidos todos los días.

Igualmente importante es su texto "Representing the Colonized", escrito específicamente para la comunidad de antropólogos en 1989. En esa conferencia Said convoca a las ciencias sociales para que continúen luchando en contra de los enormes obstáculos del imperialismo: "estoy impresionado por el hecho de que en tantos y tan variados escritos de antropología, epistemología, textualidad y alteridad, que en extensión y temas recorren la escala que va desde la antropología a la historia y a la teoría literaria, haya una ausencia casi total de referencias a la intervención imperialista estadounidense como un factor que afecta a la discusión teórica"16. Otro estimulo fundamental que podemos extraer de Said -y que exploraré al final de este ensayo- es su preocupación porque los oprimidos del mundo no se callen y reclamen siempre su derecho a narrar sus experiencias, sus insurrecciones, sus memorias, sus tradiciones, sus historias. De ahí su posición constante de insurgencia contra las tentativas de silenciar la voz de los palestinos en su lucha por salir de la situación de subalternos y de opresión a la que han sido reducidos desde la creación del estado de Israel I6. Véase Said (I989: 2I4). En verdad, Said no es el único que restaura la centralidad de la cuestión del imperialismo para una correspondencia del orden político-cultural en que vivimos. La crítica a las formas contemporáneas de imperialismo es una de las motivaciones principales para la elección de la teoría derrideana por parte de Gayatri Spivak, que llega a afirmar que "la critica al imperialismo es la propia deconstrucción" (Spivak, 1999: I08).

(véase Said, I984). 
El tercer teórico poscolonial que puede inspirar una revisión de la mirada etnográfica es Homi Bhabha. Una de sus principales contribuciones es recordarnos cuán precaria es la autoridad cultural a la que están sometidos los subalternos y los sujetos coloniales. Esa autoridad, mediante la cual somos llevados a estereotipar nuestra relación con los países centrales, se basa en el presupuesto de un orden simbólico general que es, en realidad, muy precario y frágil, como todos los ordenes culturales, susceptibles siempre de ser replanteados en cualquier nuevo acto de enunciación, bajo el signo de la confrontación. Bhabha actualiza entonces ese carácter de hibridismo que es fundacional del lenguaje y al cual se somete la actividad -ininterrumpidade traducción cultural: en sentido estricto, toda cultura es híbrida. La misma cultura dominante es híbrida en el momento en que se anuncia como autoridad.

Es el discurso el que da paso a un hiato, a un intervalo vacío parcialmente equivalente a lo que Mijail Bajtin llamó exotopía, es decir, un diálogo que no pertenece ni a mí ni al otro, sino precisamente a ese espacio exterior que es la característica misma de la relación del sujeto con la alteridad (véase Bajtin, 1990). Homi Bhabha llama a ese intervalo vacío de tercer espacio: el hiato instantáneo entre la estereotipia de la lengua y su realización viva, concreta; entre su estabilidad hegemónica y su contingencia en el momento en que se establecen las jerarquías de poder. Como ese acto es un enunciado, viene a ser justamente el lugar donde el subalterno puede capitalizar a su favor la inconsistencia simbólica dominante y devolver el carácter híbrido, precario, frágil, de ese orden que se presenta como autoridad indiscutible, legítima, superior, constante, inmutable. El lugar de ese tercer espacio será, así, el lugar dividido en que se puede esbozar un mecanismo de establecimiento de alguna especie de contradiscurso: es la posibilidad que tiene el subalterno de proponer y ejecutar una contracoherencia ${ }^{17}$. Intentaré mostrar ese esquema conceptual de Bhabha para una mirada etnográfica que explicite su política de alianzas con las voces suprimidas y silenciadas de nuestras comunidades.

Ocurre muchas veces que en el momento preciso en que el

I7. Contra-coherencia es el nombre dado por Mieke Bal (1988) a su lectura del "Libro de los Jueces" de la Biblia, desde el punto de vista de las mujeres. grupo dominante quiere presentarse como tal es obligado a reestructurar su lenguaje de dominación, de un modo contingente, coyuntural, imprevisto. Si explicita una retórica de autoridad es 


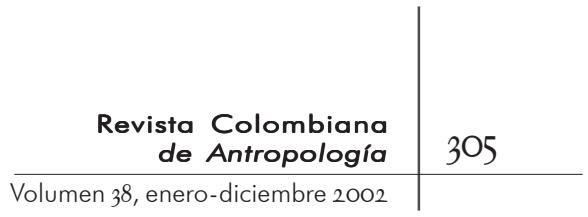

porque se ve llevado, concretamente, a ejercer su poder de control; en el preciso momento en que se desafía o repudia su fuerza, ella se articula. Sin embargo, hay siempre una negociación en términos originales e imprevisibles entre la posición del sujeto en el lenguaje y el enunciado que construye por medio de ella. Como dice Bhabha, ese es un proceso generado por la estructura misma del proceso de significación. El sujeto nunca es coetáneo al lenguaje, debido a la historicidad de la condición enunciativa. Cada enunciado -sea para expresar el poder o para confrontarlo- es siempre el resultado de la manera como el otro interpreta el signo lanzado por el sujeto. Para quien se construye en el lugar de poder -el colonialista, el imperialista, el esclavista, el latifundista-, de nada vale decir que se es poderoso, antes de una confrontación de posiciones.

Tal como entiendo, el tercer espacio es, entonces, una apertura generada entre el sistema de representación, entre la inercia codificante del lenguaje y su potencial de renovación, que se activa en una situación coyuntural. Cada vez que un enunciado de dominación -que sintéticamente podemos llamar de pretensión hegemónica- es activado, solicitado, por una instancia imprevista -un estado de emergencia o de excepción, como diría Walter Benjamin- deberá existir, necesariamente, una negociación de significado. Cuando el poderoso comienza a definirse como tal, utiliza de inmediato un significante oriundo del discurso del dominado, para marcar una polarización que debe leerse desde una perspectiva favorable a su pretensión jerárquica. El dominado tratará, entonces, de devolver al dominador una cantidad de esos significantes cargados de tensión demarcatoria de territorios. Este campo abierto de posibilidades configura un tercer espacio; y no hay modo de establecer, a priori, cuál será el resultado de esa negociación. Lo que está en juego, de hecho, es la lucha por el control de la narrativa histórica: las tentativas del dominador para silenciar la versión del subalterno y las estrategias de este para desenmascarar la versión dominante que se pretende fijar como verdadera.

Mucho más tarde surgirán las diferentes versiones de lo que fue ese momento reestructurante, que pretenderán alcanzar la condición de archivo, de memoria o de patrimonio, de costumbre o de ley: cómo se dio un conflicto en un momento determinado; de qué manera se situó el opresor; cómo rebatió el oprimido la representación que se pretendió hegemónica; y cuál fue el 


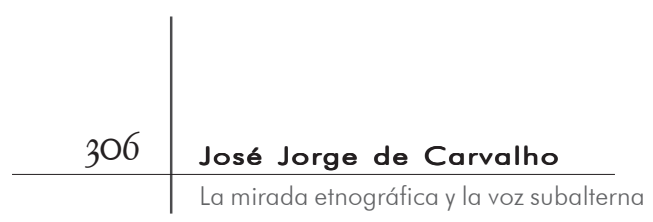

resultado de esta confrontación en varios planos: una rebelión, una masacre, la subordinación de un grupo a los intereses de otro, la reestructuración de posiciones políticas, la muerte de una comunidad, el fin de una cultura o de una forma singular de experiencia humana, etcétera. Cuando un movimiento social se aproxima a una región como es el tercer espacio, puede contar con un momento más favorable para los cambios, cuestionamientos, renovaciones, rupturas, insurrecciones, conquistas. De esta manera, Bhabha puede analizar la narrativa subalterna situándola en el plano de las identidades colectivas; por tanto, vinculando siempre su manifestación a los procesos de representación y de significación, tanto en su dimensión semiótica como en la psíquica -una de las novedades de su teoría es, justamente, proponer el entrelazamiento de estas dos dimensiones-.

Es posible que el texto de Homi Bhabha parezca siempre tan impreciso y resbaladizo porque ansía inscribirse, simultáneamente, en la tradición de la crítica literaria y cultural inglesa y en la tradición india de crítica. Lo que unifica estos dos polos de su intervención en el orden cultural establecido es la lengua inglesa, presente, aunque de un modo diferente, en las dos tradiciones discursivas. Bhabha efectúa su crítica cultural intentando construir una nación británica más abierta a la diferencia, humana y socialmente mejor. Recordemos, no obstante, que el movimiento de hibridismo que propone es fértil en el Reino Unido, donde hay garantías institucionales para el habla disidente, es decir, en donde la demanda de subjetivación está

I8. En verdad, la misma contradicción puede detectarse en la posición de Spivak. El ensayo sobre la enseñanza de literatura inglesa en su libro Outside in the Teaching Machine (I993b) fue escrito con la finalidad específica de cualificar a los alumnos que se forman en Estados Unidos -la mayoría, obviamente, ciudadanos estadounidensesFalta saber en qué medida una generación de estudiantes de literatura de ese país, mejor cualificados, influirá positivamente en el proceso de descolonización del mundo a partir del imperio.

I9. Me refiero aquí al periodo de Bhabha en el Reino Unido, porque la mayoría de los textos de su libro fueron escritos antes de su mudanza a Estados Unidos. Sin embargo, creo que el argumento que desarrollo es pertinente aún. apoyada en un sistema judicial capaz de protegerla de la intolerancia que censura y silencia. No sabemos si él sería capaz de construir, con éxito semejante, la misma demanda en el subcontinente indio, con su secuencia de regímenes autoritarios y de excepción $^{18}$. En suma, la presión que ejerce para que los británicos sean más democráticos presupone, para salvaguardar la integridad intelectual y política de Bhabha, que ellos sean demócratas en buena medida ${ }^{19}$.

En fin, una actitud común a estos tres autores es su lectura crítica de 


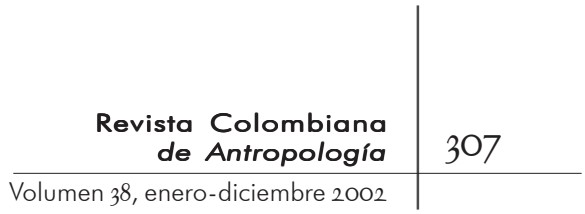

un conjunto de textos investidos de gran prestigio, por pertenecer a lo que se define y se reproduce como literatura inglesa ${ }^{20}$. A partir de ahí desarrollan esa estrategia, típica de la crítica poscolonial, de minar la autoridad, mostrar los conflictos que hay y exponer la monstruosidad promovida por ese discurso literario colonial ${ }^{21}$. En el momento, en fin, en que ellos minan esos textos de gran autoridad literaria se colocan en un espacio privilegiado del habla y tal espacio los transforma en pensadores que nos pueden inspirar, si los vemos desde la perspectiva de nuestra posición específica de subalternos. No pretendo, obviamente, desentenderme de las enormes contradicciones, justamente de tipo geopolítico, inscritas en ese proyecto de criticar la dominación imperial, denunciar el silenciamiento sistemático de habla subalterna y, al mismo tiempo, trabajar en Estados Unidos de América durante el periodo en que se consolida como el mayor imperio de todos los tiempos ${ }^{22}$. Bart Moore-Gilbert (1997) hace un análisis excelente de ese lugar crítico -desafiante, aunque heterogéneo y confuso- que llamamos la teoría poscolonial. Debemos evaluar ahora, con intensidad y sentido crítico análogos, las contradicciones y posibilidades del proyecto etnográfico en la actualidad.

Sintetizando las metamorfosis de la mirada etnográfica reseñadas, podemos decir que el estilo de la mirada de Boas y Herskovits objetivan; el estilo de la mirada de Lévi-Strauss pone distancia y aproxima, aunque manteniendo fijo el lugar hegemónico. La mirada de los llamados antropólogos reflexivos discute la autoridad del lugar hegemónico, pero su teoría de poder se limita al campo etnográfico, y esa limitación es la que Edward Said denuncia con vehemencia; dicho de otro modo, la voz del nativo aún no se considera voz subalterna. En la perspectiva poscolonial, la cuestión no es sólo la voz nativa, como la del otro diferente, sino el reconocimiento de las condiciones históricas y políticas de construcción de alteridades sometidas a un régimen colonial de subalternos. En otras palabras, se trata de deslindar los mecanismos de articulación del

2O. Terry Eagleton (I978) ha mostrado cómo se definió el canon de la literatura inglesa y cómo se expandió por el mundo, a partir de un cierto momento, hasta ser visto como el lugar de la excelencia literaria.

2I. Es el tan discutido "iHorror, horror!" que grita Kurtz en El corazón de las tinieblas de Joseph Conrad, obra literaria que ha recibido varias relecturas y reinterpretaciones que la vinculan, en una perspectiva poscolonial, a la tradición etnográfica. Véanse, entre otros, James Clifford (I986) y Chinua Achebe (I989).

22. En Cultura e imperialismo, Said se anticipa a esa cuestión y la responde abiertamente, afirmando que, en la medida en que reside en Estados Unidos, alli puede ejercer con más eficacia su responsabilidad de intelectual (Said, 1993: 54). 
nativo -el objeto etnográfico- con el etnógrafo -y sobre todo el etnógrafo de país periférico-, ambos, de hecho, en cuanto sujetos coloniales, o neocoloniales ${ }^{23}$.

\section{PARA UNA ETNOGRAFíA POSCOLONIAL Y ANTIIMPERIALISTA}

\footnotetext{
C
}

OMO SUGERí AL REMITIRME A LAS IDEAS DE SPIVAK, SAID y BHABHA, la perspectiva colonialista e imperialista de inscripción simbólica está condicionada, en su raíz, por una ambivalencia paradójica que la debilita y abre puertas para confrontarla: el texto del colonizador debe incorporar signos del universo del colonizado, lo que transforma su discurso en un texto heteróclito, con un grado problemático de desarreglo [desorden] que no es apenas estético sino, básicamente, ético: no es capaz de exorcizar lo impuro, lo ilícito, lo feo, lo horroroso, lo peligroso que se instauró en su núcleo constitutivo, so pena de debilitarse simbólicamente y dejar de ser un buen modelo de texto sobresaliente del colonizador como portador de una pretendida moralidad universal. En otras palabras, la obra-monumento del imperio nace siempre monstruosa: no puede eliminar el rastro semiótico del grupo dominado, que debe aparecer forzosamente con la señal negativa de la devaluación del ser. Eso corrobora la intuición de Walter Benjamin, inspirado en Karl Marx, de que no existe ningún documento de cultura que no sea al mismo tiempo documento de barbarie. O sea, la historia de la humanidad es un acumulado de opresiones e injusticias, cuyo clima de desastre él describió utilizando, de un modo muy original, la imagen del An-

23. Esa perspectiva, me parece, no ha sido discutida suficientemente dentro de la disciplina, a pesar de haber sido, por lo menos, delineada por Jean Rouch dos décadas atrás, lo que coloca al filme etnográfico en una posición de vanguardia en el proceso de descolonización de la antropología (véase Rouch, 1975 y 1978). Ha sido retomada, aunque parcialmente, por Michael Taussig, Paul Stoller, Janice Boddy, Jean y John Comaroff y Judy Rosenthal, entre otros. gelus Novus de Paul Klee (véase Benjamin, 1969)

Una de las estrategias poscoloniales más eficaces consiste en producir un tipo de texto -una crítica cultural, en fin-que acuse la barbarie inherente $\mathrm{y}$ fundacional de los textos monumentales del colonizador. Es lo que hacen Edward Said y Homi Bhabha en todas sus lecturas de las novelas inglesas 


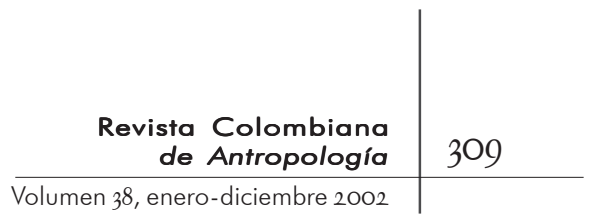

sobre India y África. Otra estrategia, utilizada también con frecuencia por Bhabha y Spivak, es referirse a textos producidos por los sujetos en procesos de descolonización: migrantes y exiliados indios, chicanos, africanos, asiáticos, etcétera, quienes acusan, en su propia naturaleza híbrida, la barbarie-monumento que los antecedió e inspiró. Es decir que, desde el punto de vista del texto cultural, generado o enunciado directamente por los grupos sociales sometidos al poder colonial -o neocolonial-, se busca resaltar su capacidad cognitiva para devolver una imagen del colonizador construida a partir de la experiencia del grupo dominado. Es posible suponer que en esos casos el proceso creativo sea tan inconsciente e intuitivo como el que experimentan los autores cómplices del orden imperial. No obstante, la estrategia de traducción cultural es deliberada: son textos producidos con la finalidad expresa de inscribir signos -con la polaridad axiológica invertida o por lo menos cuestionada- del colonizador, para desafiar el modo negativo -cuando no silenciado- con que fueron inscritos en las narrativas históricas difundidas contra -o independientemente- de sus voluntades.

Sintetizando mi lectura, todos los actores implicados en ese drama poscolonial e imperial necesitan introducir, entonces, un signo con una señal contraria en sus textualidades en relación con el otro. El dominador activa los documentos de la cultura para corroborar de un modo convincente la jerarquía que construyó: el universal abstracto, como decía Michael Taussig (I993), puede asumir una inmensa gama de fetiches o fantasmas -por ejemplo, la mujer blanca y bella de occidente, el hombre de genio, la gran obra literaria, etcétera ${ }^{24}$. Sin embargo, como se ve en los estudios poscoloniales, para fijar este orden él introduce, en algún momento, un signo del dominado, invirtiendo su valor emblemático. Debe incluirlo porque necesita presentar un orden entero, completo, de la naturaleza en la cual está inmerso y sobre la que pretendidamente reina. Cuando el dominado lee esta historia a contrapelo -esto es, cuando logra construir una especie de contracoherencia, o sea, cuando subvierte esta historia- percibe que la imagen de coherencia, de consistencia, de moral prístina del dominador es, en verdad, un Frankenstein simbólico o cultural, en la medida en que se construyó con signos articulados mediante

24. Una de las tantas controversias provocadas por Said en Cultura e imperialismo se refiere a su crítica a Dante, que colocó a Mahoma en el infierno, invirtiendo la jerarquía de su estatuto a los ojos de los seguidores de la fe musulmana. Para las réplicas a Said, véanse Ahmad (I992) y Moore-Gilbert (I997). 


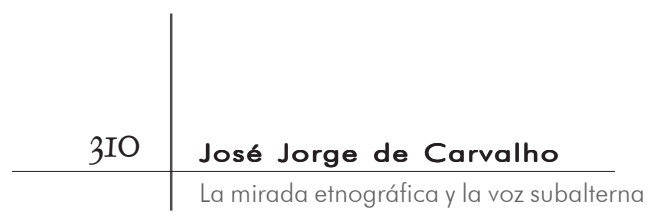

la práctica del terror, de la tragedia de los oprimidos y de los seres que el imperio tuvo que canibalizar. Como el mexicano inepto de los filmes estadounidenses del far west o el hechicero peligroso entre blancos en las historias de novelas románticas, situado en las regiones denominadas salvajes del tercer mundo; invariablemente nos encontramos con seres torcidos, monstruosos, deformes, bufones, malvados, peligrosos, impenetrables, etcétera. De esta manera, el colonizado puede reaccionar a la tentativa del colonizador de presentar esta barbarie como referencia universal de los valores más altos de la humanidad: basta que se vea a la inversa para pasar a exhibir esta monstruosidad en el centro mismo de la constelación simbólica y estética diseminada por los cuatro extremos del imperio. De acuerdo con lo que dije, aquí la deconstrucción derrideana, tachada muchas veces de mero ejercicio académico, puede tornarse un recurso discursivo eficaz en la representación de la voz subalterna.

Así, toda la historia de la humanidad puede verse como la incorporación constante de signos con señal invertida, por parte del dominador, oriundos de la expresión simbólica del dominado $^{25}$. ¿Por qué es importante este cambio de señal? Porque para el dominado esos signos secuestrados representan valores positivos, como el bien, lo bello, el sueño, la esperanza, el camino de la redención.

Incluso desde el punto de vista del dominado la opresión y la dominación sufridas se ritualizan constantemente. Él las instaura, como un evento fundador, en un proceso análogo a un kerigma tal como lo teorizó Paul Ricoeur (1974). Proyecta un evento dramático que le haga posible inscribir un signo del dominador y

25. Uso incorporación de un modo no técnico -como una imagen, primordialmente-, inspirado por tanto en el concepto psicoanalítico de incorporación desarrollado por Nicolas Abraham y Maria Torok, en sus ensayos magistrales (I986 y 1994).

26. Esta es la estrategia sistemática de las intervenciones políticas de Said, al estimular la narrativa popular palestina (Said, I984). No menos eficaces han sido las narrativas-testimonio dramáticas y articuladas, como la autobiografía de Rigoberta Menchú, texto que circuló en el mundo y atrajo la solidaridad internacional hacia la causa de los indios de América central (Menchú, 1985). trabajar el duelo que no quiere deshacerse. Traba una lucha para intentar eliminar el duelo de haber sido dominado, para inscribir el resultado de la batalla, recordar la tragedia de sus muertos, celebrar a los ancestros que claman por venganza o por un lugar decente en el cuadro de los espíritus, ya que no encontraron su debido descanso y porque el opresor no permitió que recibieran las honras fúnebres que merecían $^{26}$. Por eso debe cambiar 


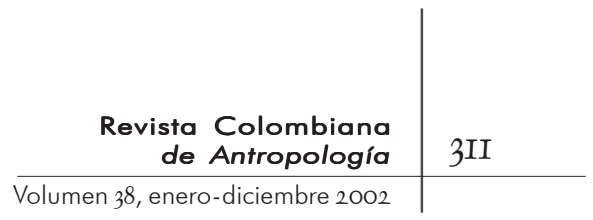

una señal. La esclavitud, el colonialismo, el imperialismo, el racismo, el neoliberalismo coercitivo fueron y son todos regímenes de destrucción. Creo que esa idea del duelo cultural, que apenas puedo esbozar en este ensayo, nos permite entender las circunstancias bajo las que ambos, dominador y dominado se incorporan.

En el caso del dominador citamos arriba el Mansfield Park de Jane Austen: la narradora no podía dejar de inscribir lo que en verdad es una monstruosidad dentro de ese orden que se pretende perfecto y, probablemente a pesar de sí misma, incorpora la esclavitud. En el caso del dominado, los innumerables rituales de inversión, los mitos fundacionales, las narrativas orales, en fin, todas las expresiones de mímesis, tan apreciadas por Taussig, y de mímica, resaltadas con frecuencia por Homi Bhabha, invariablemente ofrecen un espejo --aunque oblicuo, irónico, alegórico, indirecto, opaco- de la jerarquía poscolonial creada por los países centrales y en la que estamos todos insertos ${ }^{27}$.

Acá, en la parte inferior del mapamundi, donde fuimos colocados por la cartografía colonial, debe haber una manera de establecer un frente, recuperando inclusive varios trabajos etnográficos hechos en Brasil. Como etnógrafos somos parte de ese vasto campo de la literatura comparada. $\mathrm{Al}$ fin y al cabo, contribuimos con no poca cosa a la formación de aquello que Goethe llamaba Welttiteratur, la literatura universal en el sentido más completo, porque podemos introducir la literatura oral en todas las expresiones de balbuceo, silencio, fragmentación, en la así llamada gran literatura del mundo. Finalizaré, entonces, con dos pequeños fragmentos de narrativa oral que 27. Un ejemplo notable y perturbador de ese mecanismo de inversión de sentido es el culto de la posesión hauka de Ghana, tal como fue registrado en el extraordinario filme etnográfico de Jean Rouch, Les Maîtres Fous (I954-I955). Rouch inspiró a Michael Taussig y Paul Stoller, quienes a su vez inspiraron a Judy Rosenthal a interpretar la posesión en ese mismo sentido. Véase la discusión de la inversión hauka en su reciente etnografía sobre el trance entre los ewé (Rosenthal, I998). permiten mostrar que la importancia de los textos se da, precisamente, en ese espacio negociado entre el canon de la lengua y la posibilidad de reacción individual al enunciado, siempre histórico, particular y contingente. 


\section{NARrar la CONDICIÓN SUBALTERNA}

N I996 CONOCí EN LA Universidad DE FloRIDA A LA AgRÓNOMA NoEMI

- Porro, quien al saber que estaba escribiendo un libro sobre - los Quilombos del Rio das Rãs me contó acerca del trabajo de apoyo comunitario que efectuó en un asentamiento de mujeres que trabajaban como quebradoras de coco de babaçu, en Olho d'Água dos Grilos de Monte Alegre, Maranhão. Ella había anotado la historia de esa comunidad, que fue víctima de una barbaridad típicamente brasilera: un grileiro ${ }^{28}$ quemó las casas de varios

28. Grileiro se denomina al individuo que busca apropiarse de tierras ajenas mediante escrituras falsas. habitantes, en una de las tantas tentativas de expulsar a las familias del lugar donde vivían. Ella grabó los relatos y transcribió después las narrativas de las mujeres que contaban su lucha: cómo se atrevieron a organizarse, cómo desarrollaron sus estrategias de confrontación con el poder y, finalmente, cómo lograron el reconocimiento oficial de su tierra. He aquí que ese texto, que sucedió en la década de I870 y habla de una lucha, común en muchas comunidades brasileras, por alcanzar el reconocimiento legal de sus tierras; comienza con una pequeña historia en la que el sujeto narrador -en verdad, una narradora- cuenta sobre su abuela que murió en los años 1930. Los eventos narrados, por tanto, se refieren a los años I870. He aquí esa narrativa extraordinaria:

Mi abuela Valeriana contaba muchas historias, muchas, muchas mismo. Pero una olvida, porque olvida mismo. Porque ya fue hace mucho tiempo. Sólo la muerte de ella está con mucho tiempo, que fue en el 36 . Ella contaba que era esclava, pero no fue muy maltratada. Ella tuvo un señor, allá en Santa Isabel, que se llamaba Raymundo Onório. Ella decía que el esclavo en la hacienda de don Mundico Onório no sufría demasiado: la mujer, cuando llegaba aquellos días de ella iba para el hospital de cabeza amarrada, oído tapado, calzada y todo. Se quedaba durante ocho días.

Entonces era malo, porque era esclavo, pero tenía esa libertad por enfermedad, por manía del que no le gusta trabajar. Mi abuela aguantó mucho. Murió de vieja no de maltratada. De joven, ella vivía andando, era natural de Paraiba. Anduvo todo el tiempo para aquí, acullá, para allí. Ella contó una historia, contó así, en el camino.

Fue un viaje que ella hizo, con ese señor de ella, de un año de demora dentro de un navío: seis meses para ir y seis meses para regresar. Ella nunca supo decir cuál era la ciudad, en esa ciudad no existía negro ni 


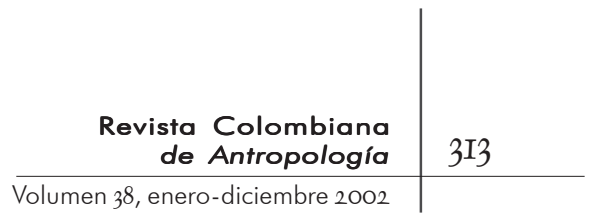

por donde. Los negros que tenían era ella y el hermano de ella, ahora ella misma no salió de la embarcación. Sólo el hermano salió para una muestra. Y ganó muchos premios por ser negro, de cabello crespo.

Considero esta pequeña historia particularmente admirable, porque permite al sujeto representarse y restituir la comprensión de un mundo más amplio que ese en el cual le fue dado moverse, y también por osar a negarse a una re-subjetivación que le es impuesta. La narradora no niega su pasado de esclavitud, habla de la abuela en cuanto esclava, aclarando que murió de vejez y no de enfermedad. Enfrenta, entonces, la esclavitud y se coloca ahora en un lugar en el que puede situarse como sujeto en los años I990, cuando cuenta la historia de la abuela. Cualquiera de nosotros puede asumir ese lugar de sujeto, dado el potencial de doble-voz de su narrativa (para la teoría de la doble-voz, véase Bajtin, 1984).

En cuanto a la subjetivación que se presenta en la modernidad o en la posmodernidad del capitalismo tardío, como diría Fredric Jameson (I99I), que es convertirse en un ser de identidad -en este caso, las negras- ella prefiere mantenerse en una posición de distanciamiento. Ella no descendió a tierra, se quedó en el navío. Prefirió ubicarse en un lugar meta, a partir del cual uno puede ponderar, por ejemplo, sobre la entrada o no en la tan discutida y ya cansona globalización. Recordemos que el mercado de coco de babaçú depende de Malasia, competidora de Brasil a escala global. O sea, se trata de un texto en portugués brasilero que habla del mundo en 200I, al mismo tiempo que de I970 y de I870. Esa capacidad de los textos subalternos, de hablar ahora y para todos, es uno de los proyectos que podemos colocar en un lugar equivalente al del tercer espacio propuesto por Homi Bhabha. Viajar y no ir, quedarse y moverse, dejarse intimidar y aceptar el desafío, llegar cerca y resistir, observar y preservarse, salir sin llegar, experimentar sin sentir, sufrir sin odiar, todo y nada en esa historia anti-kafkiana, el tercer margen del mar.

Podemos aquí, por qué no, soñar con la recuperación de una voz subalterna a la brasilera y ser capaces de agregar algo propio a los esfuerzos de los indios, africanos, árabes y oceaninos, en vez de tratar de reproducir su estilo de crítica de un modo mecánico y ahistórico. Por ejemplo, Gayatri Spivak ha optado por tejer una red discursiva que desafía al lector y le impide hallar una salida fácil para la contradicción constructiva del subalterno que 
no puede llegar a hablar, provocando así una situación de incomodidad permanente. El texto de la quebradora de coco de babaçú utiliza una estrategia inversa, de imponerse a partir de su inesperada suavidad, su afirmación, su levedad, su tono tiernamente revelador de la condición femenina de carencia de ciudadanía. Valeriana encuentra en el respeto por la maternidad un signo positivo, por el cual su narrativa cumple el papel ritual de superar el eterno retorno del duelo: no llora el horror; por el contrario, sustenta una clausura discursiva capaz de trascenderlo. El hiato de la no llegada y la interrupción del curso del viaje postergan los dolores prescritos para las situaciones de esclava o de excluida: no hay por qué lamentarse cuando no se es víctima pasiva de las circunstancias. En ese sentido, es un texto en todo distante del formato discutido por los teóricos indios citados. Y especialmente emblemático para un discurso crítico sobre la mujer oprimida del tercer mundo. Al fin y al cabo, Gayatri Spivak acaba de afirmar que "el caso típico del informante nativo que es hoy negado [en el discurso hegemónico competente de occidente] es la mujer más pobre del hemisferio sur" (Spivak, I999: 6). Al superar el duelo cultural, horizonte presente en la mayoría de los textos subalternos, las quebradoras de coco de babaçú construyen un documento de cultura que consigue no ser más un documento de barbarie, para seguir con la figura de Benjamin. En fin, en caso de existir un orden de valores humano y espiritualmente emancipado, que trascienda el colonialismo y la condición subalterna, puedo imaginarlo en el tono de voz de Valeriana.

Distribuí una copia del relato de Valeriana a los participantes de un seminario sobre teoría antropológica en Brasilia en el que se discutió el ensayo clásico de Gayatri Spivak (I993a) sobre la imposibilidad del habla subalterna (“Can the Subaltern Speak?”). Para ilustrar su polisemia y su potencial oracular transcribo, con un mínimo de edición y notas en orden cronológico de intervención, algunas reacciones de los antropólogos presentes:

Natalia Catalina León (NCL). Ella puede estar refiriéndose a un tipo diferente de esclavo, que recibía un tratamiento más suave, que sería el esclavo doméstico, distinto en todo del que trabajaba en las plantaciones y las minas. La afirmación que expresa puede venir de esa circunstancia histórica específica. El texto presenta, entonces, dos matices de la esclavitud.

Rita SEgato (RS). No necesitamos resucitar o recuperar lo acontecido; 


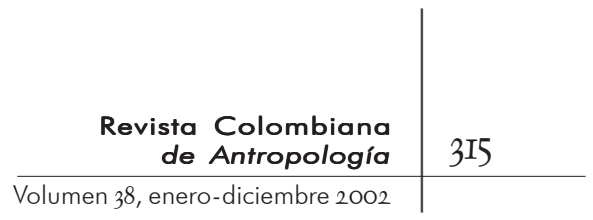

lo importante es que el relato transforma los acontecimientos de un modo positivo.

Roberto Lima (RL). Aún es un mundo de negros y blancos. ¿Por qué registrar un texto que habla de ganar premios por ser negro en los años I870, cuando se enfrentan con grileiros? De repente un negro que es valorizado frente a los blancos un siglo antes, resurge en un momento cuando tiene que traer la tierra.

RS. Es el subalterno escuchado con una voz válida.

RL. ¿Qué es lo que esa condición de subalterna trae? Trae esa premiación... lejos, donde no hay negros, porque aquí el negro está arruinado.

RS. [Como en otro proyecto de investigación que oriento], veo aquí de nuevo la relación entre la metrópoli, el poder nacional y la localidad. Es la metrópoli una vez más la que nos da una lección al premiar al negro que entre nosotros es maltratado. En esa historia hay, por tanto, una triangulación.

José Jorge (JJ). Ese texto es mítico e histórico simultáneamente; pasa en el plano que yo llamo de mit(h)istórico, una poética -imaginación ejercitada en canto o narrativa, que funda un nuevo mito-. Algo parecido con aquello que Walter Benjamin llamó de Gedichtete ${ }^{29}$.

RL. O decir, como habla el autor de Los usos de la mitología griega, que el mito es lo que era verdad. Cuando sucede el rapto de Helena, él dice: reláteme su mito; porque el mito era la versión verdadera ${ }^{30}$.

JJ. Donde ella dice: él ganó muchos premios, está diciendo, de hecho: él gana muchos premios: el ganó premios en I870 y en I970 ella gana la demanda para la reserva extractiva. Ahora el pasado es el presente en un lenguaje del pasado.

RL. Todos los significados de representación discutidos por Gayatri Spivak [Vertretung y Darstellung] aparecen en el último párrafo de esta historia: la representación política, los significados dados al negro, la autopresentación como negro.

JJ. Desde el punto de visto de la ginocrítica, a primera vista parecería que ella se queda atrás, es apenas descriptiva, mientras el sujeto agente es el hermano. ¿El hecho de no salir de la embarcación la coloca en un nivel cognitivo inferior o superior al hermano que salió? He aquí una cuestión difícil.

Siglia Doria (SD). Ella es quien posee el dominio de la historia; ella es el sujeto hablante; no fue el hermano que salió quien contó la historia; la historia es de ella.

29. Gedichtete-literalmente: aquello que fue formado poéticamente- es un término acuñado por Walter Benjamin en su ensayo sobre dos poemas de Hölderlin (Benjamin, 1996). Michael Jennings formuló una exégesis creativa de ese término, hecha como una propuesta de la crítica cultural, en su Dialectical Images: "Gedichtete como la esfera cuya utilidad es la fuente trascendental de significado y cohesión para el mundo. El objetivo de la crítica -y el de la poesía- es la mimesis o representación de esta esfera, su reconstrucción desde los fragmentos de los textos literarios" (Jennings, I987: I90).

3O. Se refiere a Ken Dowden (I992). 
JJ. El texto es un oráculo que habla sobre la globalización. Yo soy esa Valeriana. Veo el navío de Valeriana como el barco de la globalización, al cual fuimos lanzados y aquí estamos, en estado de perplejidad, sin saber si descendemos o no en la playa para donde él nos lleva ${ }^{31}$.

LADISLAO LANDA (LL). El hermano salió del barco y enfrentó el riesgo de tener éxito o no; es el dilema de la representación de la diferencia.

NCL. El otro diverso; la diferencia puede tener éxito o no.

LL. El éxito de la diferencia.

JJ, RS, NCL. La diferencia puede tener éxito.

RL. Tal vez él sólo tuvo éxito porque era solo uno, como un ejemplar único, de museo. ¿Quién sabe si ella hubiese bajado también, si ambos hubiesen tenido éxito?

NCL. Puede ser también un éxito exotizado.

JJ. Que ella no quiso, al que ella se negó; yo creo que ella sabe más. RS. Ella no prestó oídos al lado malo y entendió la exotización como un éxito. Ella sólo escuchó lo que era bueno. Eso es una estrategia.

JJ. Ella no siguió el canto de sirena.

LL. El hermano de ella es como uno de los personajes de los que habla Montaigne en el ensayo sobre los caníbales y todos los indios que fueron llevados a Europa, la admiración que despertaron allá ${ }^{32}$.

JJ. Pero ahí fue terrible; nosotros no tenemos su testimonio; fueron subalternos que no pudieron devolver a su comunidad su lugar en la historia.

RS. No, ellos se transformaron en los evolués de que habla Edward Said $^{33}$.

LL. Hicieron traducciones [de textos indígenas].

RS. Fueron los intermediarios comprometidos con la colonia. Fueron interlocutores privilegiados del colonizador, que aprendieron sus categorías, para contarle sobre su mundo, vertido ya para las categorías del colonizador. Son esos evolués; el hermano sería el negro que habla para el blanco.

JJ. Ella no es eso.

RS. Ella habla para instalar un lugar, un valor, una posición, un perfil. Ella es diferente. El intelectual no puede eludir su obligación de

3I. Tema discutido por mí al final de otro ensayo (Carvalho, I996a).

32. Se refiere al ensayo de Michel de Certeau (I986)

33. Said: "Representing the Colonized: Anthropology's and its interlocutors" (I989: 208). escuchar, de rescatar ese silencio del subalterno.

JJ. La abuela y la nieta están hablando ahora. El sujeto heroico, victorioso, que reproduce el discurso dominante, deja cosas fuera, siempre silencia algo. Yo, como brasilero que vivo en la fase posesclavismo del país me siento implicado en el discurso de ella(s), hago mía su voz. 


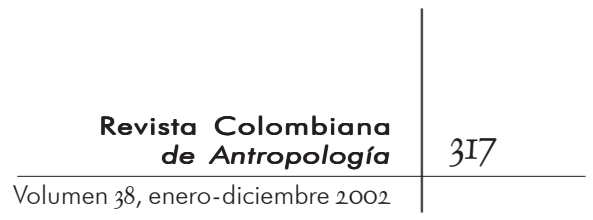

La nieta incluye la voz de la abuela y el antropólogo se incluye en la voz de la nieta.

RS. El no silenciamiento del intermediario: yo digo para qué estoy trayendo el texto. El intermediario sospechoso es aquel que borra su presencia. Solamente cuando yo digo para qué estoy trayendo la voz [nativa, subalterna] es que no la traiciono. El antropólogo entiende el interés de la abuela en relatar lo que relató, el de la nieta en recordar el relato y re-relatarlo; y el etnógrafo ve su interés en traerla ahora, las dos voces para el presente, para mi texto. Una cadena de intermediarios interesados.

LL. El nativo también edita el interés del presente.

JJ. Valeriana se puso en el lugar meta, desde donde está comentando la competencia entre Brasil y Malasia, competencia que a su vez es controlada en Suiza, en la Organización Mundial de Comercio, donde Brasil tiene que hacer, con muchos obstáculos, su lobby para sobrevivir a los grandes controladores de la riqueza mundial: Estados Unidos, Japón, Alemania.

RS. Usted está detrás del discurso del subalterno.

JJ. Que es mi discurso.

EDna Alencar. ¿Qué voz es esta, en cuanto subalternos?

RS. Spivak habla lo que la gente piensa que habla cuando hace antropología. Sólo que los antropólogos de los países centrales no lo hacen. Nosotros somos mucho más parecidos a lo que Spivak hace: intentamos colocar al subalterno para hablar -la voz que nunca se escucha, la voz inaudible, inscribir esas voces que no están inscritas, hacer un registro de lo que la historia no cuenta-. Y este no es el quid de la antropología de los países centrales, es nuestra antropología, ellos no están implicados en nuestro mundo. Es muy raro que no nos impliquemos en lo que hacemos. Y cuanto más aprendemos el corte de ellos, vamos perdiendo esa implicación.

SD. Si usted habla como el colonizador, entonces se desterritorializa, y ahí se queda sin lugar. Va a participar de una comunidad que es idealizada, sin frontera, sin ancla. El investigador que viene de lejos.

JJ. Él hasta puede implicarse, pero es diferente, es otro tipo de implicación.

RS. Él escribe para una comunidad de iguales que es un ejercicio, un experimento de conceptos, como decía Said; un experimento intelectual, en el que aquella orquestación de descripciones simplemente tenga sentido. Él garantiza un lugar en aquel medio intelectual y académico, porque el conjunto de descripciones que trae tiene sentido allá. Pero no queremos tener sentido solamente allá. Y cada vez corremos este peligro: el Ministerio de Educación nos coloca este peligro con nuestra evaluación en la universidad brasilera: ¿cuántos artículos que usted escribió fueron publicados en el exterior? Entonces somos forzados cada vez más a pensar en los 
interlocutores de allá y cómo van a escuchar ellos lo que estamos hablando. Y se vuelve difícil conservar las dos lealtades, la de hablar para allá, que es necesario también, no la estoy negando, pero colocando esa voz en la cual yo estoy implicada, desde mi situación de subalterna y de mis subalternos [coterráneos de destino], que yo represento, incluso en las dos formas discutidas por Spivak: represento como Vertretung y como Darstellung, porque estoy implicada.

\section{TRADUCIR LA VOZ SUBALTERNA}

XISTE UN ÚlTIMO TEXTO, QUE ES EN REALIDAD UN PRETEXTO, UN SUB-

texto, un motivo, una evocación de un acto que marcó la - vida de la comunidad -y en alguna medida marcó mi vida después de conocerlo- lo que no sólo fue narrado por una mujer, sino sirvió también para inscribir una sensibilidad que podemos calificar de femenina a ese movimiento social.

Cuando el oficial de policía quemó todas las casas, vino la jueza de Monte Alegre a exigir que las mujeres abandonasen el poblado destruido. Entonces, una de las mujeres se aproximó a la jueza y le dio un leve coscorrón en la cabeza, para llamarle la atención sobre la injusticia que estaba contribuyendo a perpetuar. La quebradora de coco exigió a la jueza que tuviese más simpatía por las mujeres: ella, una mujer que también parió, debería entender el sufrimiento de esas mujeres pobres y agraviadas. La jueza lloró al recibir el coscorrón y cambió: instantáneamente determinó las medidas que deberían tomarse para cesar las hostilidades contra la comunidad y alejó del horizonte cualquier amenaza de desalojo y de legalización del grilaje. Al final de la lucha, Olho d'Água dos Grilos alcanzó el estatuto, hacía tanto soñado por sus habitantes, de reserva extractiva.

Podemos preguntar cuál es el estatuto literario de esa serie arbitraria de relatos pasados a maquina y agrupados por una grapa. ¿Embrión de libro? Por lo menos debemos reunirlos y divulgarlos como comentarios apócrifos. Su conjunto propondrá la sabiduría de nuestras comunidades y, tal vez, hagamos con ellos una especie de Talmud babilónico, de Torá alternativa; o como si fuese una nueva serie de hadiths, recientemente compilados y que comentan una vez más la historia sagrada del profeta, o incluso, un nuevo conjunto de apócrifos sobre la historia de Jesús. Una pieza polifónica abierta y que se construye en el 


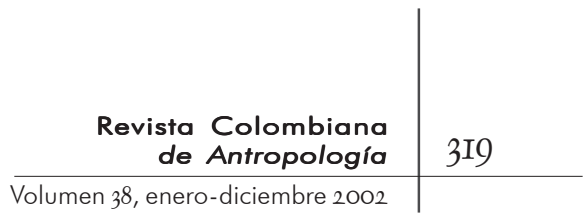

hiato entre el silencio y la acción que apunta a liberar al sujeto de su condición subalterna. Y en la medida en que privilegia esos umbrales, en varios planos -histórico, individual, natural, político- se torna sorprendentemente próxima del ideal contemporáneo de la ficción del espacio intermediario, tal como la teoriza Claudia Egerer (1997).

Como dije, la estrategia más común de crítica cultural propuesta por los investigadores de literatura comparada ha sido sugerir relecturas de obras escritas, canónicas, consagradas o silenciadas por algún motivo ideológico o político. Mi propuesta complementaria para nosotros, los etnógrafos, es que oigamos e intentemos inscribir las voces aún no inscritas en el canon. En el caso de esos relatos, ellos ejercitan la propiedad más instigante de cuantas Mijail Bajtin (1984) consiguió identificar en su análisis de la textualidad humana: la inacababilidad (para una exégesis de ese concepto, véase Gary Morson, 1990). No fueron terminados cuando fueron contados en la selva entre las mujeres, no se cerraron cuando fueron dactilografiados por Noemí Porro y no se cierran aquí, cuando los transcribo en medio de una discusión teórica.

Existe otra asociación un tanto original que puede establecerse aquí. La narrativa de Valeriana atañe también a la experiencia del Unheimliche, de lo extraño, de lo insólito, de lo no familiar. Toca, primero, el Unheimliche en su sentido freudiano, dado el insólito acto de estar en casa en un barco extraño. Luego habla del Umheimliche en el sentido más literal en que hoy se discute la condición desterritorializada de los exiliados, migrantes o trabajadores estacionales, asunto apreciado por autores tan diversos como Homi Bhabha, Arjun Appadurai y Néstor García Canclini. Y en tercer lugar, ella toca el Umheiliche en el sentido extremadamente creativo que le confiere Martin Heidegger en sus notas del curso que impartió sobre el poema "El Ister”, de Hölderlin, en I942. Ella alcanza la condición liminal de lo extraño y, extrañamente, no lo vive; o mejor, vive lo extraño como una experiencia de lo familiar: no se perturba con lo que irrumpe en su horizonte de conocimiento. Invierte, así, la proposición que Heidegger atribuye a Hölderlin, de ver como extraño para sí lo que era familiar para los griegos. Tal vez, Valeriana muestra que no es necesario descender de las tradiciones lingüísticas griega y alemana para expresar ese desenraizamiento constitutivo de la experiencia histórica humana. Así es como el 
comentario de Heidegger parece de pronto apto y próximo de su narrativa: "la historicidad de toda la humanidad reside en ser enraizado (Heimliche), y ser enraizado (Heimliche) es sentirse en casa (Heimliche) al ser desenraizado (Umheimliche)" ${ }^{34}$. Enraizada, es el desarraigo que la arraiga y le hace crear raíces que hablan por ella, que cuentan su historia, como lo hace su nieta, a quien escuchamos.

Los tres autores que discutí nos estimulan, por lo menos implícitamente -en caso de que su pensamiento sea capaz de influenciarnos-a que nosotros, los etnógrafos, devolvamos al mundo unos textos que se sitúan con la radicalidad cognitiva que ellos buscan identificar en los sujetos heterodoxos de la sociedad occidental. Homi Bhabha resalta a Tony Morrison, Derek Walcott, Nadine Gordimer -tres premios Nobel de la periferia del mundo inglés-y a Salman Rushdie, centro de una de las mayores controversias político-literarias del mundo contemporáneo. Edward Said recupera, entre otros, a Jean Genet y al historiador Basil Davidson. Está claro que no necesitan concederle prestigio a sus narradores. Gayatri Spivak utiliza su prestigio para colocar en el mapa imaginario de la llamada alta literatura a Mahasaweta Devi, hasta entonces desco-

34. Martin Heidegger, Hölderlin's Hymn "The Ister", p. I25. Texto de Heidegger según la traducción de William McNeil y Julia Davis: "... la historicidad de cualquier clase de género humano reside en ser familiar, y ser familiar es un llegar a ser familiar en lo extraño".

35. Como señala Homi Bhabha, "El estudio de la literatura mundial puede verse como el examen de la manera en que las culturas se reconocen a sí mismas mediante sus proyecciones de alteridad. Allí donde la transmisión de tradiciones nacionales fue una vez el tema central de una literatura mundial, podemos ahora sugerir, tal vez, que las historias transnacionales de inmigrantes, de gente colonizada y de refugiados políticos -estos límites y condiciones fronterizas- pueden ser los terrenos de la literatura mundial [hoy]" (I992: I46). Hago mías las palabras de Homi Bhabha, con la advertencia de que no es necesario pensar sólo en el espacio transnacional: en nuestros países, el silenciamiento sistemático de voces se ejerce constantemente dentro del espacio nacional. nocida en occidente. Existe un paralelismo, entonces, en este esfuerzo por expandir infinitamente el ámbito de la diferencia en la Weltliteratur ${ }^{35}$.

Podemos usar los mismos recursos que ya utilizamos como etnógrafos; por tanto, se espera una mayor conciencia de estas posibilidades de politizar el espacio discursivo que se abre constantemente cada vez que nos atrevemos a intervenir como sujetos en la cadena de representación activada por los grupos subalternos, para reabrirla antes de que se congele, sea en forma de cultura incorporada y confinada a nuestro grupo exclusivo de pertenencia, sea por la rutina de su uso como emblema estereotipado-cuando no reificado-de identidad étnica, comunitaria, racial, de género, etcétera. 


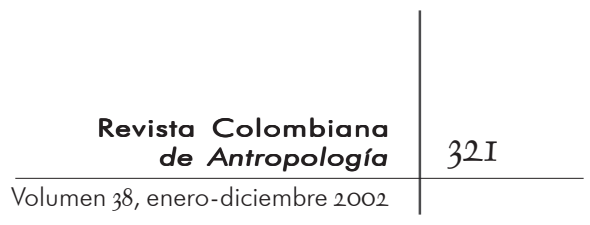

Y en cuanto a la Weltliteratur, se basa en la traducción cultural, en el sentido que le da Walter Benjamin (I969), actividad familiar a nosotros, los etnógrafos. Se trata de producir gramáticas que puedan ser utilizadas en un sentido emancipador de las comunidades puestas al margen de los recursos del estado, al cual están atadas legalmente. Cuando se discute el hibridismo, el no esencialismo, el tercer espacio, la descolonización, etcétera, todo presupone una dimensión terapéutica de la palabra argumentativa que incentive la autoestima ${ }^{36}$. El proceso de atribuir significado a un significante cualquiera implica siempre un grado de alienación, en el sentido de alejamiento, distanciamiento, descarte, rechazo de una parcela de su potencial significativo. Es por eso que lo expresivo excede el significado y la traducción cultural se impone dentro de la tradición nativa al enfrentarse con la tradición discursiva dominante. En esta área de lo expresivo el texto cultural es más poderoso y más polisémico, de modo que el sujeto subalterno pueda apropiarse de él con mayor creatividad y poder de persuasión. Mircea Eliade (1969) menciona en uno de sus textos las raras situaciones en que una narrativa visionaria puede cumplir las funciones de trascendencia, comúnmente asociadas a las acciones rituales concretas. De esta manera interpreta el bello estudio de Henry Corbin (I979) sobre la narrativa visionaria de Avicena, con la cual la narrativa de las mujeres quebradoras de coco puede llegar a dialogar en la inusitada dimensión del mundus imaginalis.

Obviamente, es común que las narrativas orales adquieran un carácter fragmentario -esta es su forma de presentación más común -. Empero, son justamente estos fragmentos los que hablan de la condición de subjetividad, los que inscriben las relaciones jerárquicas de poder que configuran nuestra realidad. Aquí nuestra estrategia es parcialmente inversa a la estrategia poscolonial: no se trata de revisar el cuadro de significación -siempre caóticode las obras literarias prestigiosas y consagradas de los países centrales, sino de inscribir las obras -conjuntos de fragmentos- anónimas de nuestras poblaciones. Y el acto de inscribirlas no debe entenderse como un acto neutro, puramente académico $^{37}$. El efecto de las narrativas debe hacerse sentir, antes que nada, en el propio etnógrafo: él debe dejarse afectar por un discurso que se presenta como extraño, distante, inacabado,

36. Aquí tal vez, finalmente, el nihilismo radical de Steve Tyler encuentre su dimensión política de positividad (Tyler, I986).

37. En otro ensayo desarrollo con más detalle las estrategias conceptuales de identificación y proyección del etnógrafo frente a las narrativas subalternas (Carvalho, 1999). 


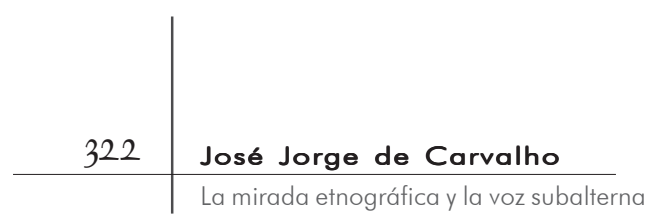

inadecuado, por tanto, desarraigado, paria, desencadenado, abierto a la alteridad, con una vocación irreductiblemente universalista.

Así, la mujer dio un coscorrón en la cabeza de la jueza: golpeó el juicio de la jueza, la mandó a tomar juicio. Al contrario del arma de fuego usada por los hombres para eliminar hombres y mujeres y no para transformarlos en seres humanos mejores, la quebradora de coco abrió el coco de la mujer poderosa sin quebrarlo. Como el toque de pulgar del maestro Zen en la cabeza del discípulo, que tanto fascinó a Victor Turner cuando describió el toque del maestro de ceremonia del Chihamba en la cabeza de los neófitos ndembu, hubo allí quizás una apertura del tercer ojo, un pasaje a un plano superior de humanidad, que es el ejercicio de la fraternidad, de la solidaridad y de la justicia. Fue este el coscorrón que recibí al entrar en contacto con estos relatos. Doy un coscorrón en ustedes que me leen.

\section{BibLIOGRAFÍA}

Achebe, Chinua. 1989. "An image of Africa: Racism in Conrad's Heart of Darkness". En Hopes and Impediment's: Selected Essays. Doubleday. Nueva York.

- I990. "A História das Terras de Monte Alegre e de Olho D’Água dos Grilos. A Memória Oral das Mulheres Quebradeiras de Côco Babaçu”. Manuscrito organizado por Noemi Porro.

Ahmad, Aijaz. 1992. In Theory: Classes, Nations, Literatures. Verso. Londres.

Baines, Stephen. I995. "Primeiras impressões sobre a etnologia indígena na Australia”. En Roberto Cardoso de Oliveira y Guilhermo Raul Ruben (organizadores). Estilos de Antropología. Editora da Unicamp. Campinas.

. "Social Anthropology with Aboriginal Peoples in Canada: First Impressions”. Serie Antropologia, $\mathrm{n}^{\circ}$ 167. UnB. Brasilia.

Bajtin, Mijail. I990. Art and Answerability. Traducción de Vadim Liapunov y Kenneth Brostrom. University of Texas Press. Austin.

- 1997. Problemas da Poética de Dostoiévski. Forense Universitaria. Rio de Janeiro.

Bal, Mieke. 199I. Reading Rembrandt: Beyond the Word-Image Opposition. Cambridge University Press. Cambridge. 


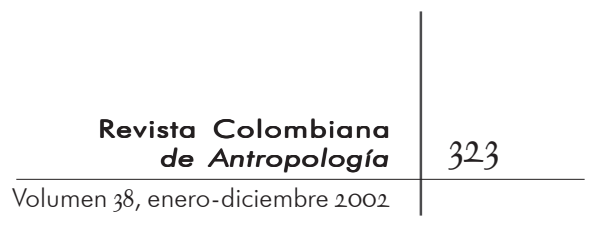

1998. Death and Dissymetry. The Politics of Coherence in the Book of Judges. The University of Chicago Press. Chicago.

Benjamin, Walter. 1969. "The Task of the Translator". En Illuminations. Editado por Hannah Arendt. Schocken Books. Nueva York. . 1985. "Sobre o conceito da História". En Obras Escolhidas. Magia e Técnica, Arte e Política. Brasiliense. São Paulo.

—. I996. "Two Poems by Friedrich Hölderlin". En Selected Writings. Volume I, I9I3-I926. The Belknap Press of Harvard University Press. Cambridge.

Внавна, Номi. 1992. "The World and the Home”. Social Text. 31/32

— . I994. The Location of Culture. Routledge. Londres . I996. "Culture’s In-Between". En Stuart Hall y Paul du Gay (organizadores). Questions of Cultural Identity. Sage Publications. Londres.

Carvalho, José Jorge. I996a. “Globalization, Traditions, and Simultaneity of Presences”. En Luís Eduardo Soares (organizador). Cultural Pluralism, Identity, and Globalization. Unesco|ISSC|Educam. Rio de Janeiro.

I996b. "Quando o objeto vira sujeito". En Vagner Gonçalves da Silva, Letícia Vidor de Souza Reis y José Carlos da Silva (organizadores). Antropologia e seus Espelhos. A Etnografia Vista pelos Observados. Programa de Pós-Graduação em Antropologia Social. São Paulo.

_ I997. "Imperialismo Cultural Hoje: uma Questão Silenciada”. Revista USP. 32.

. I999. "O Olhar Etnográfico e a Voz Subalterna". Serie Antropologia. 261. Departamento de antropología, Universidad de Brasilia.

- 200Ia. Traducción y coautoría. "Os Dilemas do Poder na Representação Etnográfica”. Serie Antropologia. Departamento de antropología, Universidad de Brasilia.

- 200Ib. "Inscrição do sujeito e construção de identidade nas narrativas das comunidades negras tradicionais". Serie Antropologia. Departamento de Antropología, Universidad de Brasilia.

Clifford, James. 1986. The Predicament of Culture. University of California Press. Berkeley.

Corbin, Henry. 1979. Avicenne et le Recit Visionnaire. Berg International. París. 
Danius, Sara y Stefan Jonsson. 1993. "An interview with Gayatri Spivak". Boundary 2.

Devi, Mahasweta Draupadi. I988. En Gayatri Spivak. In Other Worlds. Essays in Cultural Politics. Routledge. Londres.

- 1995. Imaginary Maps. Three Stories. Traducción de Gayatri Chakravorty Spivak. Routledge. Londres.

DERRIDA, JACQUeS. I97I. "A estrutura, o signo e o jogo no discurso das ciências humanas". En A Escritura e a Diferença. Perspectiva. São Paulo.

. 1997. El monolingüismo del Otro. Manantial. Buenos Aires.

Diawara, Manthia. ig95. Rouch en Reverse. Documentário. Newsreel. San Francisco, CA.

Dowden, Ken. 1992. The Uses of Greek Mythology. Routledge. Londres.

Duarte, Luís Fernando. 2002. "Dias Antropologia e Psicanálise". Trabajo presentado en el Simposio "Antropologia e psicanálise: um encontro possível?", en la XXII Reunião da Associação Brasileira de Antropologia, Brasília, julio.

Dussel, EnRique (organizador). I994. Debate en torno a la ética del discurso de Apel. Diálogo filosófico Norte-Sur desde América Latina. Siglo Veintiuno. México.

Eagleton, Terry. 1978. Criticism and Ideology. Verso. Londres.

Egerer, Claudia. 1997. Fictions of (In)Betweenness. Acta Universitatis Gothoburgensis. Gotemburgo.

Eliade, Mircea. 1969. The Quest. History and Meaning in Religion. University of Chicago Press. Chicago.

GeERTz, Clifford. I989. "Um Jogo Absorvente: Notas sobre a Briga de Galos Balinesa”. En A Interpretação das Culturas. Guanabara Koogan. Rio de Janeiro.

-. 1995. After the Fact. Harvard University Press. Cambridge. . 200I. Nova Luz sobre a Antropologia. Jorge Zahar. Rio de Janeiro.

Goethe, J. W. 1986. "On World Literature". En Essays on Art and Literature. Suhrkamp Publishers. Nueva York.

Guha, Ranajit (editor). 1997. A Subaltern Studies Reader. I986-I995. University of Minnesota Press. Minneapolis.

Hall, Stuart. 1996. "Cultural Identity and Diaspora". En Padmini Mongia (organizador). Contemporary Postcolonial Theory. A Reader. Arnold. Londres.

Heidegger, Martin. 1996. Hölderlin's Hymn "The Ister”. Traducción 


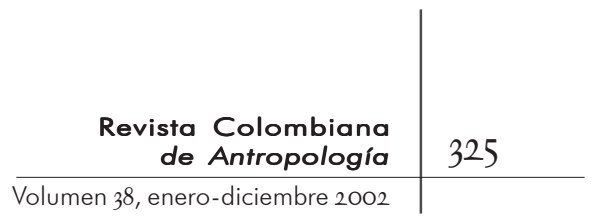

de William McNeill y Julia Davis. Indiana University Press. Bloomington.

JAMESon, Fredric. 1989. The Ideologies of Theory. Essays. Vol. i y 2. University of Minnesota Press. Minneapolis.

- I99I. Postmodernism, or the Cultural Logic of Late Capitalism. Duke University Press. Durham.

- 1992. O Inconsciente Político. Editora Ática. São Paulo.

Krauss, Rosalind. I993. The Optical Unconscious. Mit Press. Cambridge.

LACAN, JACQUES. I998. "O tempo lógico e a asserção da certeza antecipada”. En Escritos. Jorge Zahar. Rio de Janeiro.

Latin American Subaltern Studies Group. 1993. "Founding Statement”. Boundary 2. Volumen 20: 3.

Latouche, Serge. 1996. A Ocidentalização do Mundo. Vozes. Petrópolis.

Lévi-Strauss, Claude. 1996. Tristes Trópicos. Companhia das Letras. São Paulo.

Marcus, George. I997. "Critical Cultural Studies as one Power/ Knowledge like, among others, and in engagement with others". En Elizabeth Long (organizadora). From Sociology to Cultural Studies: New Perspectives. Blackwell. Oxford.

. 1998. Ethnography through thick and thin. Princeton University Press. Princeton.

Marrouchi, Moustapha. i998. "Counternarratives, Recoveries, Refusals”. Boundary 2. Vol. 25: 2.

Menchú, Rigoberta. 1985. Me llamo Rigoberta Menchú y así me nació la conciencia. Siglo Veintiuno Editores. México.

Mignolo, Walter. I994. "Are subaltern studies postmodern or postcolonial? The politics and sensibilities of geo-cultural locations". Dispositio/n. 46.

- I995. The Darker Side of the Renaissance. The University of Michigan Press. Ann Arbor.

- 1996. "Herencias coloniales y teorías postcoloniales". En Beatriz González Stephan (organizadora). Cultura y Tercer Mundo. I. Cambios en el saber académico. Nueva Sociedad. Caracas.

1998. "Posoccidentalismo: el argumento desde América Latina”. Cuadernos Americanos. Nueva Época. 67. Volumen I, enero-febrero. 
Moore-Gilbert, Bart. 1997. Postcolonial Theory. Context, Practices, Politics. Verso. Londres.

Morson, Gary. I990. Mikhail Bakhtin: Creation of a Prosaics. Stanford University Press. Stanford.

Ngugi Wa Thiong'o. I98r. Decolonizing the Mind. Heineman. Londres.

— . 1982. Devil on the Cross. Heineman. Londres.

—. 1989. Matigari. Heineman. Londres.

Niranjana, Tejaswini. 1992. Siting Translation. History, poststructuralism and the colonial context. University of California Press. Berkeley.

Nugent, Stephen y Chris Shore. I997. Anthropology and Cultural Studies. Pluto Press. Londres.

Oliveira, Roberto Cardoso. I998. O Trabalho do Etnógrafo. Editora Paralelo I5. Brasilia.

Oliveira, Roberto Cardoso y Guilhermo Raul Ruben (organizadores). 1995. Estilos de Antropologia. Editora da Unicamp. Campinas.

Peirano, Mariza. i995. "Desterrados e exilados: Antropologia no Brasil e na Índia”. En Roberto Cardoso de Oliveira y Guilhermo Raul Ruben (organizadores). Estilos de Antropologia. Editora da Unicamp. Campinas.

Rabinow, Paul. I983. "Humanism and Nihilism: The Bracketing of Truth and Seriousness in American Cultural Anthropology". En R. Bellah, N. Hann, P. Rabinow y W. Sullivan (editores). Social Science as Moral Inquiry. Columbia University Press. Nueva York.

Ricoeur, Paul. I974. Conflict of Interpretations. Northwestern University Press. Evanston.

Rosenthal, Judy. 1998. Possession, Ecstasy, and Law in Ewe Voodoo. University Press of Virginia. Charlottesville.

Rouch, Jean. I954-I955. Les Maîtres Fous. Documentário etnográfico. Interama. Nueva York.

- I975. "The Camera and the Man”. En Paul Hockings (organizador). Principles of Visual Anthropology. Aldine. The Hague/Chicago.

- I978. "On the vicissitudes of the self: the possessed dancer, the magician, the sorcerer, the filmmaker, and the ethnographer". Studies in the Anthropology of Visual Communication. Vol. 5: I.

RUTHERFORD, JonATHAn. "O terceiro espaço. Uma entrevista com Homi Bhabha". Revista do Patrimônio Histórico e Artístico Nacional. 


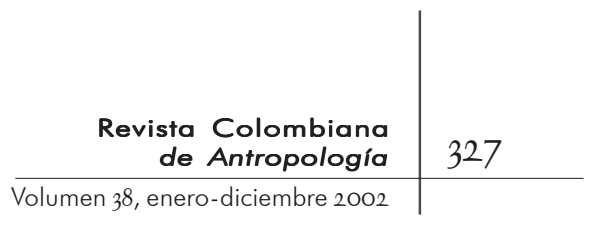

SAID, EdWARd. I984. "Permission to narrate". London Review of Books, 16-29 de febrero.

— . I989. "Representing the Colonized: Anthropology's Interlocutors". Critical Inquiry. 15.

- 1993. Culture and Imperialism. Chatto \& Windus. Londres.

Sardar, Ziauddin. 1998. Postmodernism and the Other. The New Imperialism of Western Culture. Pluto Press. Londres.

Segato, Rita. I998. "La economía del deseo en el espacio virtual: conversando cristianismo en el internet". En Elio Masferrer Kan (organizador). Sectas o iglesias. Viejos o nuevos movimientos religiosos. Plaza y Valdés. México.

Silva, Vagner Gonçalves. 2002. O Antropológo e sua Magia. EDUSP. São Paulo.Silva, Vagner Gonçalves y Letícia Vidor da Silva Reis (organizadores). A Antropologia e seus Espelhos. Pós-Graduação em Antropologia, USP. São Paulo.

Silverman, Kaja. 1996. The Threshold of the Visual World. Routledge. Londres.

Soares, Luiz Eduardo. 1999. "Metamorfose e unidade sintática em um mundo só". Interseções. Revista de Estudos Interdisciplinares. I. UERJ.

Spivak, Gayatri. I990. "Pratical Politics and the Open End". En The Post-Colonial Critic: Interviews, Strategies, Dialogues. Routledge. Nueva York.

_. 1993a. "Can the subaltern speak?". En Patrick Williams y Laura Chrisman (editores). Colonial Discourse and Post-Colonial Theory. A Reader. Harvester Wheatsheaf. Hemel Hemsptead.

I993b. "Scattered Speculations on the Question of Cultural Studies". En Outside in the Teaching Machine. Routledge. Londres.

- 1999. A Critique of Postcolonial Reason. Harvard University Press. Cambridge.

Stoller, Paul. 1992. The Cinematic Griot. The Ethnography of Jean Rouch. The University of Chicago Press. Chicago.

Taussig, Michael. 1993. Mimesis and Alterity. A Particular History of the Senses. Routledge. Nueva York.

Torok, Nicolas Abraham y Maria Torok. 1986. The Wolf Man's Magic Word: A Cryptonimy. University of Minnesota Press. Minneapolis.

- 1994. The Shell and the Kernel: Renewals of Psychoanalysis. University of Chicago Press. Chicago. 
Turner, Victor. I975. "Chihamba the white spirit: a ritual drama of the ndembu". En Revelation and Divination in Ndembu Ritual. Cornell University Press. Ithaca.

Velho, Otávio. I995a. Besta-Fera: Recriação do Mundo. Relume Dumará. Rio de Janeiro.

. 1995b. "De novo, os valores". En Besta-Fera: Recriação do Mundo. Relume Dumará. Rio de Janeiro.

. I998. "Dilemas profissionais da comunidade antropológica brasileira". Texto presentado en la mesa redonda sobre teoría antropológica de la Associação Brasileira de Antropologia. Vitória. Abril. 